\title{
Evaluation of a Practice Change to Improve Screening, Identification, and Management of Patients with Prediabetes
}

\author{
Murrita C. Bolinger \\ West Virginia University
}

Follow this and additional works at: https://researchrepository.wvu.edu/etd

\footnotetext{
Recommended Citation

Bolinger, Murrita C., "Evaluation of a Practice Change to Improve Screening, Identification, and Management of Patients with Prediabetes" (2012). Graduate Theses, Dissertations, and Problem Reports. 3627.

https://researchrepository.wvu.edu/etd/3627

This Dissertation is protected by copyright and/or related rights. It has been brought to you by the The Research Repository @ WVU with permission from the rights-holder(s). You are free to use this Dissertation in any way that is permitted by the copyright and related rights legislation that applies to your use. For other uses you must obtain permission from the rights-holder(s) directly, unless additional rights are indicated by a Creative Commons license in the record and/ or on the work itself. This Dissertation has been accepted for inclusion in WVU Graduate Theses, Dissertations, and Problem Reports collection by an authorized administrator of The Research Repository @ WVU. For more information, please contact researchrepository@mail.wvu.edu.
} 
Evaluation of a Practice Change to Improve Screening, Identification, and Management of Patients with Prediabetes

\author{
Murrita C. Bolinger, MSN, FNP-BC
Doctoral Research Project submitted to the School of Nursing
at West Virginia University
in partial fulfillment of the requirement
for the degree of

\author{
Doctorate \\ of \\ Nursing Practice
}
Alvita Nathaniel, PhD., FNP-BC, Chair
Jarena Kelly, DNP, FNP-BC
Frank Schwartz, M.D.
Department of Nursing
Morgantown, West Virginia
2012

Keywords: diabetes prevention, prediabetes, electronic medical record reminders 


\section{Abstract \\ Evaluation of a Practice Change to Improve Screening, Identification, and Management of Patients with Prediabetes \\ Murrita C. Bolinger, MSN, FNP-BC}

Background: The prevalence rate of type 2 diabetes among adults in West Virginia (WV) is 10.85, which ranks fourth in the United States in 2007. Furthermore, WV ranks as second highest state for diabetes related deaths in the nation. Prediabetes increases the risks for development of type 2 diabetes. Studies have supported lifestyle modification education for prediabetic adults in an effort to reduce progression to type 2 diabetes.

Objective: To evaluate the use of an EMR reminder to improve the screening, identifying, and documentation of treatment plans for patient at risk for prediabetes.

Methods: A provider focused education session was offered to heightened awareness about prediabetes and provide instruction on the implementation of a new EMR reminder for prediabetes. An EMR was activated for an eight week intervention period. Data was collected from 100 randomly selected pre- and post- intervention chart audits.

Population: The population for this capstone project focused on adults 25 to70 years old within the Wirt County Health Service Association who meet the criteria for prediabetes by American Diabetes Association (2012) medical standards.

Expected Outcomes: The evaluation of the EMR reminder will improve screening, identifying, and documenting treatment plans based on critical appraisal of current literature. 


\section{Acknowledgements}

To God, I dedicate my life, work, and career to You. I pray that I put my best foot forward in all I do to bring You praise. Thank you, Lord, for putting beautiful people in my life. People who care, pray, and love me through my life’s journey.

I would like to personally acknowledge the following:

My Capstone Chair, Dr Alvita Nathaniel and committee members, Dr Jarena Kelly and Dr Frank Schwartz: for your support in my endeavor to move toward expertise in diabetes prevention and the management of diabetes so I may make a difference in the healthcare field.

My parents: for their love, dedication, and encouragement to me and my family. I love you!

My NUMC Youth Leaders: for picking up the slack and keeping our youth program "alive” in Christ and your support in "Praying Me Through."

My classmate, Diane Ladd: for your example of being a DNP and your scholarly guidance. Most importantly, my husband and children: for the hugs and kisses and understanding of my time needed to complete this high honor of becoming a DNP. Your support and staying up with me during late night typing was special moments that I will not forget. I love you! 


\section{Table of Contents}

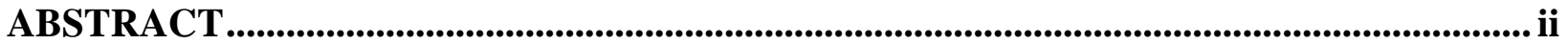

ACKNOWLEDGEMENTS ….......................................................................................

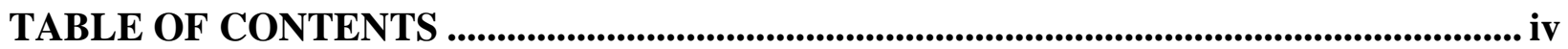

CHAPTER I: INTRODUCTION ............................................................................... 1

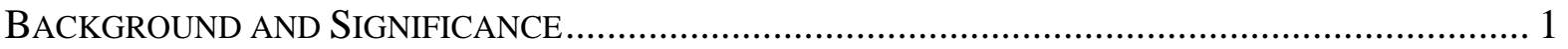

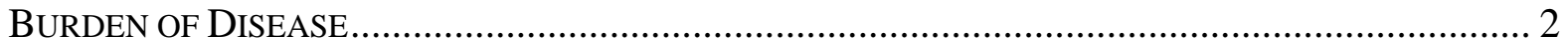

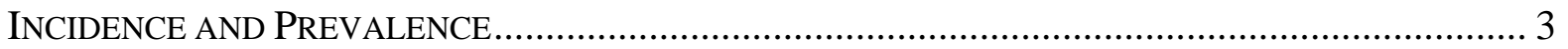

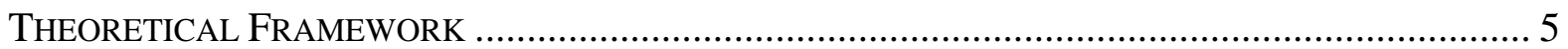

CHAPTER II: REVIEW OF LITERATURE ............................................................ 12

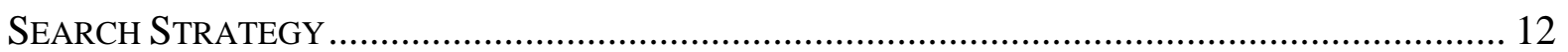

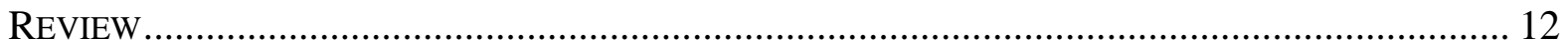

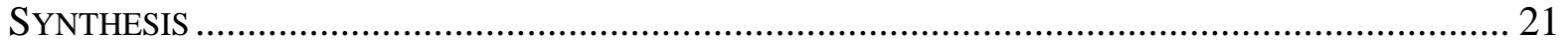

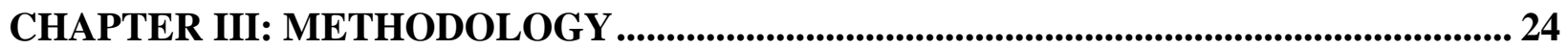

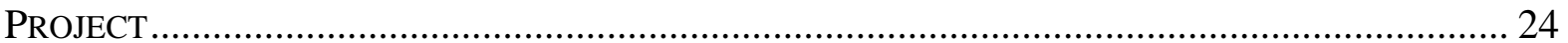

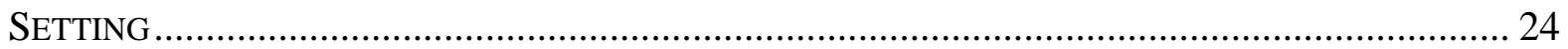

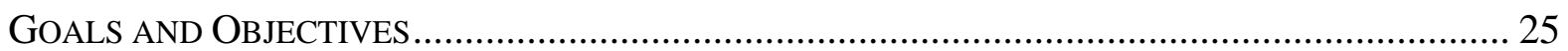

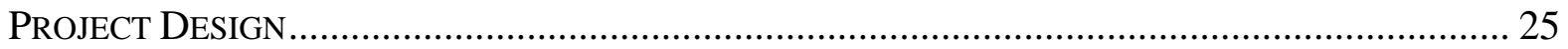

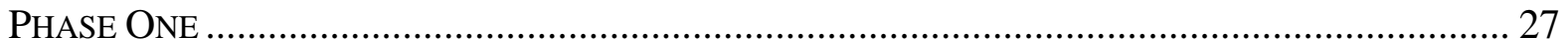

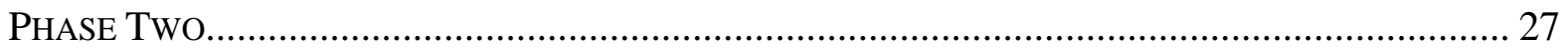

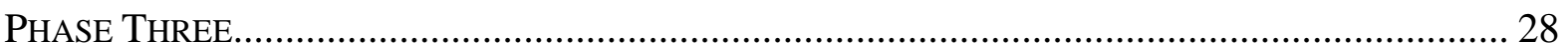

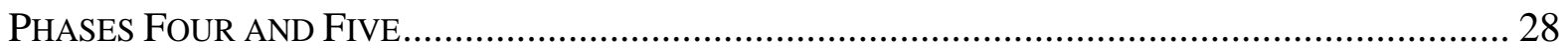

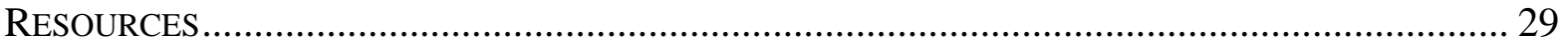

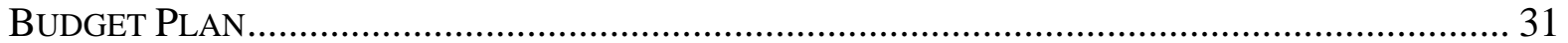

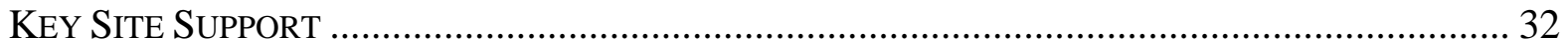

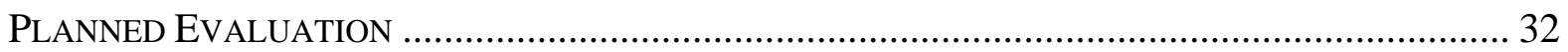

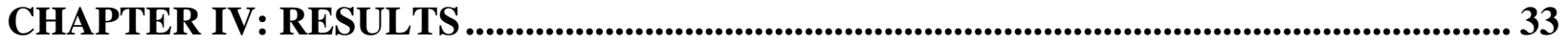

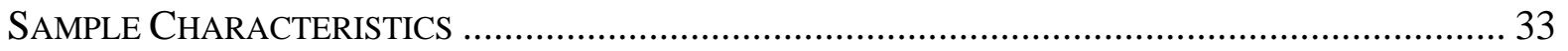

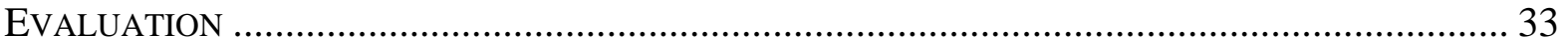

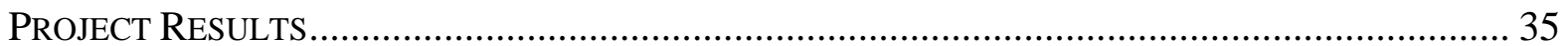

CHAPTER V: SUMMARY, DISCUSSION, AND IMPLICATIONS .................................. 39

CONGRUENCE WITH THE THEORETICAL FRAMEWORK …….................................................. 39

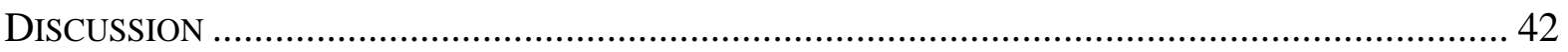

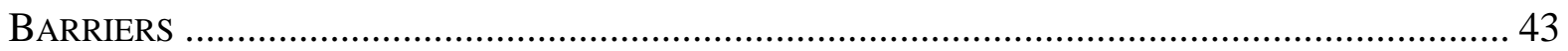

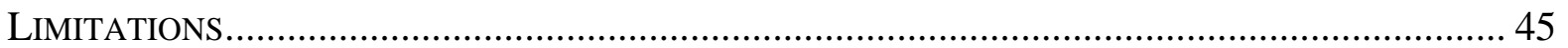

Implications for Practice. .......................................................................................... 46

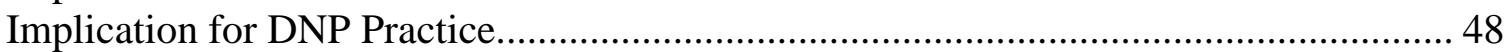

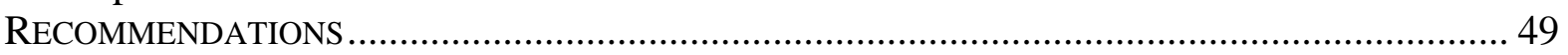

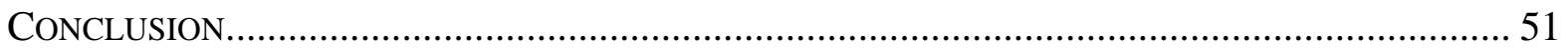

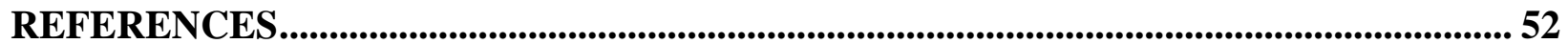




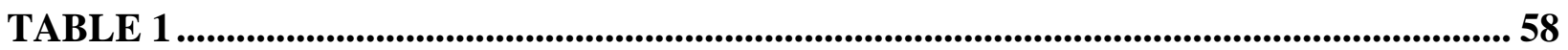

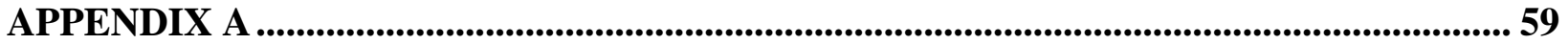

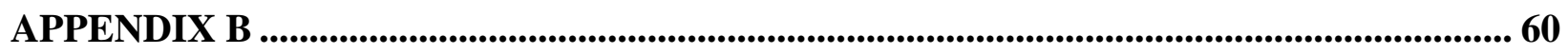

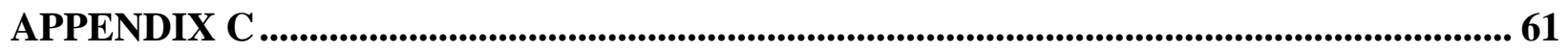

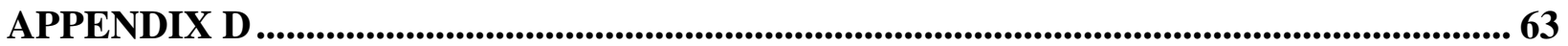

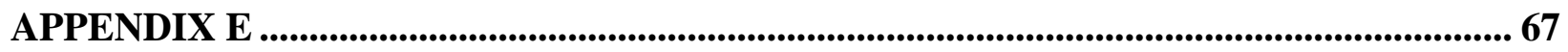

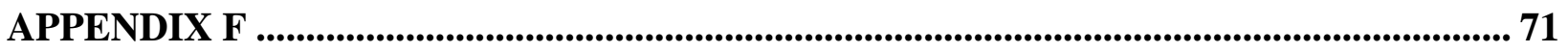

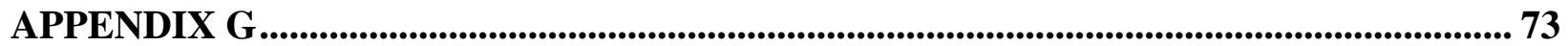

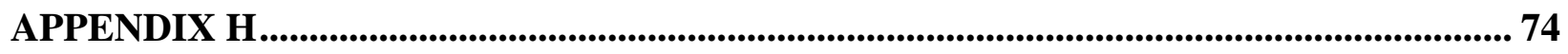

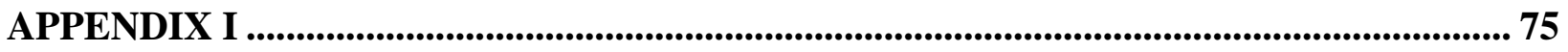

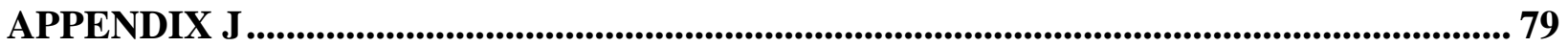

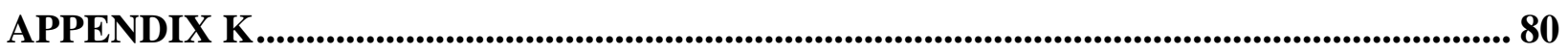




\section{Chapter I: Introduction}

Diabetes was the seventh leading cause of death in 2007, contributing to a total of 231,404 deaths in the United States (Center for Disease Control and Prevention [CDC], 2011). This number may be higher as the National Institute of Diabetes and Digestive and Kidney Disease (NIDDK) states the number of deaths from diabetes is underreported (2008). The majority of deaths among diabetics are related to macrovascular and microvascular complications (Winer \& Sowers, 2004). The Diabetes Prevention Program (DPP) has demonstrated that early intervention in the prediabetic stage can prevent or delay the onset of type 2 diabetes (DPP, 2002). This paper includes background and significance, relevant literature of review, and a theoretical framework that underpins the detailed description of the proposed practice change, which includes an educational component for providers.

\section{Background and Significance}

Diabetes is a significant health problem in the United States (U.S.). The CDC (2011) estimates that one in three adults living in the U.S. could develop diabetes mellitus by 2050. People with prediabetes have a five to fifteen times greater risk of developing type 2 diabetes (Agency for Healthcare Research and Quality [AHRQ], 2005). Prediabetes is underdiagnosed, undertreated, and without proper intervention leads to type 2 diabetes creating a risk of significant morbidity and financial burden for patients and society.

The American Diabetes Association (ADA) 2012 recognizes a group of individuals atrisk for type 2 diabetes. This disorder has been labeled “prediabetes.” Individuals with prediabetes have glucose levels that do not meet the criteria for diabetes, yet are higher than considered normal. The ADA (2012) medical standard of care defines prediabetes as, "impaired fasting glucose (IFG) ranging $100 \mathrm{mg} / \mathrm{dl}$ to $125 \mathrm{mg} / \mathrm{dl}$ or impaired glucose tolerance test (IGT) with blood drawn two hours after a loading dose of glucose in a oral glucose tolerance test 
(OGTT) of 140mg/dl to 199mg/dl” (p.S13). A third parameter suggested by the ADA directs providers to inform individuals of their risk of developing diabetes by using the measure of glycated hemoglobin (A1C) within the range of 5.7-6.4\% as another marker for prediabetes. Any one of these three determinants provides a definition of prediabetes. When providers identify prediabetes, recommendations should be made for lifestyle changes and management, which helps prevent type 2 diabetes (Kulzer, Hermanns, Gorges, Schwarz \& Haak, 2009; Norris, Zhang, Avenell, Gregg, \& Schmid, 2005; Yamaoka \& Tango, 2005).

People with prediabetes can lower the risk of developing diabetes. The DPP included clinical trials at 27 health centers throughout the U.S to evaluate lifestyle modification versus pharmaceutical interventions on prediabetes. All participants were tested and diagnosed with prediabetes. This 2.8 year study found that intensive lifestyle modification (healthy eating, exercise, and subsequently weight loss) reduced the incidence of type 2 diabetes by $58 \%$ as compared to medication with metformin by 31\% (Diabetes Prevention Program Research Group, 2002). This landmark study inspired the Diabetes Prevention Program Outcomes Study (DPPOS). A ten year follow-up with approximately $88 \%$ of the eligible participants from the original study supported the findings. The incidence of type 2 diabetes remains lower in the lifestyle group over time (Diabetes Prevention Research Group, 2009).

\section{Burden of Disease}

Diabetes impacts the physical, social, psychological, and economic aspects of individuals, families, communities, and populations. People with prediabetes and diabetes are at increased risk for developing heart disease, stroke, hypertension, pregnancy complications, periodontal disease, depression, and other illnesses (Bureau for Public Health, 2009). The CDC (2011) reports the risk of death among people with diabetes is about twice that of people of a 
similar age without diabetes. The CDC further reports the effects on disabilities associated from diabetes. Sixty to seventy percent of people with diabetes have a form of neuropathy leading to 82,000 lower limb amputations each year (CDC, 2011). Prediabetes and complications of diabetes negatively impact people’s health and life expectancy.

The economic impact of diabetes is significant. The national cost of diabetes in U.S. in 2007 exceeded \$174 billion (ADA, 2008). The United Health Group’s (2010) economic report projects that the national cost will rise to $\$ 500$ billion by 2020 . Medical expenditures are on average 2.3 times higher for people with diabetes in comparison to those without diabetes (CDC, 2011). Increased costs are attributed to diabetes complications and treatment of these conditions. Therefore, supporting measures to promote the prevention of type 2 diabetes will directly impact healthcare spending as well as the mortality and morbidity associated with diabetes and its complications.

\section{Incidence and Prevalence}

The number of people who have undiagnosed prediabetes is staggering. The CDC estimated that $35 \%$ of adults ages 20 years and older and $50 \%$ of adults ages 65 and older have prediabetes (2011). This means that approximately 79 million Americans have prediabetes. The CDC indicates that 7\% are unaware that they meet the criteria for prediabetes (2011).

Unfortunately, limited data is available on the rates of prediabetes at the state, regional, and local level as universal screening is not currently a practice standard.

Prediabetes, typically under diagnosed, is a precursor of type 2 diabetes. Nearly two million people over the age of 20 were newly diagnosed with diabetes in 2010 (CDC, 2011). Data collected from the CDC’s Behavioral Risk Factor Surveillance (BRFSS) is based on selfreporting, which may carry an under-reporting bias. People were classified as undiagnosed if 
they were without a history of diabetes followed by testing of fasting blood glucose (FG), IGT, and A1C. The estimated figures do not include adults with diabetes less than one year from diagnosis, those who refused to respond, or those who do not know that they have diabetes.

The prevalence of diabetes in the U.S. was estimated at 18.8 million adults in 2010. The National Diabetes Fact Sheet (2011) estimated that seven million adults over the age of 20 with diabetes are undiagnosed. Rates among males and females are similar with $11.8 \%$ and $10.8 \%$ respectfully (CDC, 2011). The mean age of diabetes, diagnosed and undiagnosed in 2010, was 52.4 (male) and 53.4 (female) years (CDC, 2011).

West Virginia (WV) ranks higher than the national statistic for diabetes. The America's Health Rankings (2011) reported that WV was ranked $48^{\text {th }}$ in the total adult population with diabetes. In addition, the WV Health Statistics Center (2007) reports $11 \%$ of the total population had the diagnosis of diabetes and another $2 \%$ had prediabetes. By comparison, in the U.S., the prevalence of diabetes was $8.6 \%$ of adults (BPHSC, 2009). The WV Health Statistics Center (2007) estimates that an additional 85,000 have diabetes but are unaware of their diagnosis in this state report (WV Health Statistic Center, 2007). In a 2009 report from the Bureau for Public Health Statistics Center (BPHSC), the prevalence rate of diabetes among WV adults ages 18 years and older was 10.8\% with 156, 300 people diagnosed with diabetes in 2007.

Consequently, WV ranks as the $2^{\text {nd }}$ highest state for diabetes related deaths in the U.S. (WV Health Statistics Center, 2007).

The incidence and prevalence can also be seen on a local level. One facility within Wirt County Health Service Association (WCHSA) saw 2,912 who were over the age of 20, and of those patients 1,031 were uninsured. During a one year period, this facility captured the International Statistical Classification of Diseases and Related Health Problems (ICD-9) codes 
for both controlled and uncontrolled type 2 diabetes. This 2009 report identified 1,787 patients with type 2 diabetes. Interestingly, of 4,047 patients seen during that year, the ICD-9 codes for prediabetes identified only four cases, further supporting the claim that prediabetes is underreported (WCHSA, 2009).

National, state, and local data indicate that diabetes is a serious health problem. Further, the ADA guidelines identify prediabetes as a precursor to type 2 diabetes (2012). It is the ADA position that lifestyle and medication may prevent prediabetes from progressing to type 2 diabetes. Therefore, the question guiding the proposed project was: Does a provider focused education program and an electronic medical record (EMR) reminder improve screening, identification, and plans of care for patients with prediabetes?

\section{Theoretical Framework}

Rogers Diffusion of Innovations Theory served as a framework to guide the development, implementation, and evaluation of this proposed project. This theory supported the implementation of a practice change of screening, identifying, and implementing plans of care for patients with prediabetes. Rogers developed the conceptual framework in 1962 to explain how, why, and at what rate new ideas and technology will spread through a system.

Elements of Diffusion. Rogers (1995) describes the elements of diffusion of an innovation as the communication process, planned or spontaneous, by which an innovation is spread through certain channels over time among members of a system. The system is comprised of a group of people with a shared goal to overcome a particular problem (Rogers, 1995). The diffusion framework involves several concepts. These concepts explain human and social nature related to how potential new information is utilized. This theory draws from psychology and rural sociology (Rogers, 1995). 
Diffusion of Innovation Process. Rogers Diffusion of Innovation complex theory proposes a process in adoption of a new idea within a social system. The theory is based on a five step linear process that moves through knowledge, persuasion, decision, implementation, and confirmation as seen in Table 1. The first step is knowledge which involves gaining, learning, and recalling information specifically to the innovation. The persuasion step is characterized by a person forming positive or negative opinions about the innovation. During the decision step, the innovation is accepted or rejected. The implementation step occurs when the innovation is utilized. The fifth step is confirmation. Individuals will evaluate, modify, and integrate the innovation as ongoing routine based on the recognition of benefits. The decision making process starts with the first step of knowledge that has three sub-stages. Awareness knowledge imparts basic knowledge about the specific innovation. Application knowledge is information needed to know the innovation to work within the social system. Principle knowledge is the understanding of why and how the innovation is important to the participant's role. Knowledge ties the relative advantage factor to the innovation by explaining what and how.

Characteristics of Adopters. Adoption of a new idea is influenced by characteristics of adopters. The rate or speed at which a new idea will be adopted will also depend on the reciprocal interaction of the adopters. Rogers (1995) classifies individuals as innovators, early adopters, early majority, late majority, and laggards. The innovator is the first to adopt the new idea. The innovator or project leader must convey competence in the area of needed change. This individual plays an important role in launching the new idea by importing the innovation from outside the social system. The theory posits that the innovator or change agent serves as a gatekeeper to motivate the social system in the decision-making process. 
Categories of people who lead change are individuals within the social system.

Following the lead of the innovator, the early adopter serves as a role model for other members in the social system and adopts the innovation quickly and judiciously. Change agents seek out early adopters due to their influence as leaders. Early adopters are instrumental in reaching a concept that Rogers (1995) describes as critical mass. Critical mass is the final concept in the Diffusion of Innovation Theory. The concept of critical mass occurs when enough individuals have adopted the innovation and the innovation becomes self-sustaining (Rogers, 1995).

Among the four other categories, other adopters approach change differently. The next category of adopters is early majority, who seldom lead. The early majority adopts a new idea before the average member of a unit, but only after deliberating over the innovation. Late majority individuals adopt a new idea typically based on increasing network pressure. The late majority and laggards approach innovations with caution. Laggards possess no opinion leadership. Decisions for laggards are based on what has been done previously. A tendency to be suspicious regarding the change agent and innovation is a characteristic of laggards.

Factors Affecting Adoption of the Innovation. Each step is influenced by characteristics of the adopters and the innovation. Rogers' (1995) theory predicts that an organizations "readiness" will be supported or not supported by several factors that affect the rate of adoption. These factors include relative advantage, compatibility, complexity, trialability, and observability. Providing a system with knowledge about the innovation will lead to "reduction in uncertainty." Relative advantage is the perceived benefit of the innovation within the system. Compatibility takes into consideration aspects of work flow. The innovation needs to fit into the existing system with minimal labor intensive steps. In addition, the practice change must mesh with values, beliefs, and needs of the current system. The factor of complexity deals 
with the complexity or simplicity of the innovation relative to the system. Brainstorming with different disciplines within the organization will provide vantage point to simplify the proposed project and trouble-shoot barriers. The staff's perception of an innovation as simple will increase the likelihood of faster adoption.

Finally, innovations are more likely to be adopted if they can be piloted without requiring user commitment. Rogers (1995) terms this factor as trialability. Observability can stimulate peer discussion and user acceptance. Eliciting feedback through informal conversations or during meetings encourages high visibility of innovation results. Observability may further convince those that need "proof" that the innovation will function properly. "Buy-in" occurs when the benefit of the innovation is visible to the adopters.

Projects using Rogers Theory. Rogers Diffusion of Innovation has been used in adoption of new ideas involving computers. Carlfjord and colleagues (2010) studied a new innovation of computer-based testing for a lifestyle intervention. Based on Rogers Diffusion of Innovation, this qualitative study analyzed key factors for influencing adoption. The implementation strategies used were an information session, a one month test period, and causal opportunities to provide feedback to opinion leaders. A follow-up information session included how the new tool would be used in daily routine and a mutual agreement was reached on feedback issues. Data were collected after nine months. Staff was invited by email to a focus group interview. The findings revealed that adoption was positively influenced by knowing expectations, compatibility with existing routine and perceived advantages. This study used a convenience sample which carries a selection bias. The total staff participation in the focused group interviews were 67 members of six primary health care units in Sweden. The findings of this study supported the Diffusion of Innovation factors of relative advantage, compatibility, 
complexity, and trialability.

A comparison study uses Rogers Diffusion of Innovation Theory in cardiometabolic risk factors among patients treated with antipsychotic medications. The study addressed the strategies to disseminate knowledge of risk and management approaches to lower risk of adverse cardiometabolic outcomes by implementing glucose screening protocol (Nicol et al., 2011). Antipsychotic medications are associated with hyperglycemia risk. This study used the Roger's Diffusion of Innovation Theory. After an education program, key individuals were identified to actively participate in solving the clinical problem of low glucose screening rates. Education programs can influence relative advantages by allowing feedback and open discussion of workflow with the new innovation. The comparison site received initial education of the protocol and reminders to screen their patients before appointments only. The quality improvement approach included several staff of different job descriptions. The medical director set the target monthly screening rates. The pharmacy assisted in flagging patients who were treated with antipsychotic medications. Medical records personnel under supervision assessed baseline screening rates. The medical director along with the medical staff developed a bestpractice glucose screening protocol.

Observability was a highlighted concept used in this study. Besides using awareness knowledge and developing protocols for practice application, observability was an attribute to influence adoption in the study by Nicol et al (2011). These authors reported the baseline glucose screening rate was $46 \%$. The overall glucose screening rates increased to $67 \%$ after the initial education program, monthly medical meetings, and electronic newsletters. The screening rate further increased to $90 \%$ after the second intervention of site visits from the Medical Directors. Information collected on the screening practices by primary providers contributed to 
this rise in percentage. The comparison clinic was 26\%-38\% lower than screening rates at all four outpatient clinics during the same month. Results need to be interpreted with caution. Limitations noted were new and existing patients were not differentiated, and patient characteristics were not evaluated, which may have influenced the use of glucose screening. A third study found combining Rogers Diffusion of Innovation and the Theory of Planned Behaviour was helpful in adoption of a behavior change. Scott and colleagues (2008) examined physicians' utilization of a Canadian Heart Health Kit (HHK) and factors that shaped its adoption. Interestingly, these authors used both Rogers Diffusion of Innovation Theory and the Theory of Planned Behaviour. A sample of 153 physicians agreed to participate. The physicians were given the HHK, and two months later, a study questionnaire to assess attributes of the HHK and their intention of using the kit in clinical practice. Relative advantage and the observability of the HHK benefits were significantly associated with physicians’ intent to use the HHK. Relative advantage was measured by the response that the HHK was more effective than the current practice. Rogers Diffusion of Innovations concept of observability was supported by the conclusions from Scott and colleagues 2008 research. The authors found that the benefits of using the HHK with patients and the practice were made visible to the physicians promoted use. The authors received 115 survey questionnaires. The relationship among the variables indicated trialability $0.44(\mathrm{p}<0.001)$ and observability $0.34(\mathrm{p}<0.001)$. The variables relative advantage $(\beta=0.27 ; p<0.05)$ and observability $(\beta=0.27 ; p<0.05)$ were significantly associated with intentions $\left(\mathrm{R}^{2}=0.47 ; \mathrm{p}=0.01\right)$. Physicians in solo practices reported experiencing more individual and environmental barriers to using the HHK. The authors attribute this finding to lack of access to colleagues that hindered the ability to dialogue about the new innovation. 
Limitations of this study include short term adoption of the kit and the use of a small convenience sample.

Hader et al. (2007) used the Diffusion of Innovations Theory as a framework to examine the views of doctors on implementation of clinical practice guidelines (CPGs). Forty-five doctors were interviewed about their attitudes, opinions, and behaviors regarding the CPG. The doctors identified key influences in adopting an innovation in their practice. First, they needed to know the guideline existed. Secondly, the guideline should address an area in which perceived change was needed. Thirdly, the participating doctors discussed the importance with opinion leaders and respected colleagues that supported the proposed CPG. The authors further found that the doctors valued that the CPG was based on scientific evidence that demonstrates improved health outcomes for patients without increasing risks. Knowing that the patients and families accepted the changes indicated by the CPG were also important to the doctors. Finally, the practice change needed to be supported by the system in technology, resources, and training.

The Diffusion of Innovations Theory identifies characteristics that foster the process of adopting a practice change. The success of a practice change depends on the individual's response or "buy-in” to the proposed change. Identifying champions or early adopters who are respected within the system will encourage the adoption of utilizing the EMR reminder to support quality health care. Most individuals may not evaluate a new idea based on research evidence. According to Rogers Diffusion of Innovation Theory, the subjective evaluation of early adopters to accept or reject the innovation has the power to influence others in the social system. Communication throughout the project will be essential for the social system to promote understanding of the change concept. 


\section{Chapter II: Review of Literature}

\section{Search Strategy}

The search to identify the best evidence related to electronic medical record (EMR) reminders to improve screening, identification, and documentation of the treatment plan for patients with prediabetes was conducted using National Guideline Clearinghouse, Cochrane Library, and Ebscohost (Academic Search Complete, CINAHL, Health Sources

Nursing/Academic Edition, and Medline). Keywords used for the search included: prediabetes, diabetes prevention, impaired fasting glucose, EMR prompts and reminders, and Diffusion of Innovations. No limits were placed on diagnosis or clinical settings. The initial search of key words: EMR reminders, diabetes prevention, and prediabetes identification yielded 1867 hits. The search was narrowed by using different combinations of the keywords, using English language only, and selecting studies from peer reviewed journals between the years of 20052012. This revealed a total of 66 hits. This was narrowed again by reviewing the abstracts for specific use of EMR reminders or prompts in the studies yielding 26 documents. Hand searching (snowballing technique) was used from reference lists of relevant articles. A total of nine articles were identified as appropriate for this project.

\section{Review}

A critical appraisal was conducted on each of the nine documents using the tools from the Scottish Intercollegiate Guideline Network (2008). Nine studies were selected for this review based on the strength of evidence and relevance to the question. The nine studies included five RCTs (Feldstein et al., 2006; Gill, Chen, Glutting, Diamond, \& Lieberman, 2009; Loo et al., 2011; Player et al., 2010; Sequist et al., 2005), one quasi-experimental study (Shelly et al., 2011), two pre-post intervention studies (Hunt et al., 2009; O’Connor, et al., 2005), and one prospective descriptive study (Riley, Galang, \& Green, 2011). These were assessed for internal validity, 
overall assessment of the study, and description of the studies. An evidence table was developed to summarize the findings of the studies and is available upon request. All five RCTs (Feldstein et al., 2006; Gill, Chen, Glutting, Diamond, \& Lieberman, 2009; Loo et al., 2011; Player et al., 2010; Sequist et al., 2005) examined the adherence to national guidelines featuring the use of EMR reminders.

Feldstein et al. (2006) evaluated the use of the EMR reminder to increase guideline recommended osteoporosis care after bone fracture. There were fifteen primary care clinics and 159 providers in the study. The participants $(n=327)$ were randomly assigned to group one (EMR reminder), group two (EMR reminder plus educational letter mailed to patients), or group three (usual care). Usual care was defined as follow up with the patient's chosen provider who received a discharge summary after the bone fracture. The two intervention arms received a patient-specific EMR reminder reviewing clinical guideline advice regarding osteoporosis medication and bone mineral density (BMD) measurements to follow-up care. The study did not mention any training prior to EMR reminder implementation. The EMR reminder was initiated by the chairman of the osteoporosis quality-improvement committee. The study arm received an advisory letter with educational materials on osteoporosis prevention. Information was sent to both provider and patient. After six months, group one (EMR alone) resulted in $51.5 \%$, group two (EMR reminder plus written patient education materials) resulted in $43.1 \%$, and usual care resulted in 5.9\% of patients receiving BMD measurements or osteoporosis medications ( $\mathrm{p}<$ 0.001). Compared to usual care, EMR reminder increased the probability of receiving a BMD measurement by 0.39 (95\% confidence interval $(\mathrm{CI})=0.28-0.50)$, and BMD or medication by 0.47 (95\% CI =0.35-0.59). Strengths associated with this study included: well defined inclusion and exclusion criteria; study groups that were stratified using a design adaptive 
randomization that balanced age and fracture type; and the study analyst assessing the outcomes was blinded to treatment groups. The study also had noted weaknesses. First, the participants from a single nonprofit health maintenance organization (HMO) reduced generalizability to other populations. Second, the study nurse and participants were not blinded to group assignment allowing for potential bias.

Gill, Chen, Glutting, Diamond, and Lieberman (2009) evaluated the effects of EMR reminders on lipid management in primary care. Treatments were based on Adult Treatment Panel-III (ATP-III) guidelines. A total of 105 physicians from 25 offices and 64,150 patients were included in the study. The main intervention incorporated the use of EMR reminders to initiate a three page computer tool. The tool included 1) over-due notices for lipid testing, 2) recommendations for patients' lipid goals based on ATP III guidelines, and 3) a management page to add or change medications, order additional testing, or document patient education. Training prior to the implementation of the EMR reminder was not discussed. However, physicians were excluded if they had exposure to an EMR-based lipid management form. The results showed that the intervention group was more likely than the control group to have lipid testing at the end of the one year study period $(\mathrm{p}<0.05)$. After controlling for confounding variables, only up-to-date lipid testing for high-risk patients in the intervention group was statistically improved compared to the control group (adjusted odds ratio 15.0, $\mathrm{p}<0.05$ ). The univariate analyses showed significant increases for most outcome measures in both the intervention and control group. Plausible explanations for this finding included patients in the control group were more likely to be younger ( $p<0.0001)$, male $(\mathrm{p}<0.0001)$, and at low risk ( $\mathrm{p}$ $<0.0001)$. The study did not measure the use of the EMR tool. Another potential reason was a ceiling effect. According to the authors, the baseline parameters were already high, leaving less 
room for improvement. Additionally, other limitations would include an underestimate of the management intervention if prescription or lab tests were ordered on paper. Identified study strengths include large sample size and the overall study design using randomization within blocks of similar practices to avoid contamination due to patient sharing among the providers. The power analysis indicated that 350 patients were needed to achieve $80 \%$ power to detect a $10 \%$ difference between the intervention and control group. The authors propsed that having automated EMR reminders can help facilitate "a team model of care” by involving staff in the implementation process. This approach, in their opinion, would foster a less disruptive workflow and is necessary for the tool to be effective.

Two RCT’s mentioned training sessions prior to implementation of the EMR reminder process (Loo et al., 2011; Player et al., 2010). Loo et al. (2011) conducted a one year longitudinal study to evaluate recommended preventive care guidelines for the elderly. Three arms of the study included EMR reminder, EMR reminder plus panel manager, or control group. In this study, 4666 patients met the inclusion criteria. Outcome measures included four practice behaviors: designation of a health care proxy, osteoporosis screening, and administration of pneumococcal and influenza vaccinations. A panel manager's role was to assist in completing the four practice behaviors by communicating reminders to physicians by email and to patients by phone and then by letter if no response. Loo et al. (2011) found that EMR reminders were effective in achieving higher rates of health care proxy designations, osteoporosis screening, and administration of influenza and pneumococcal vaccinations. EMR alone facilitated significant improvement in vaccination rates for influenza $(\mathrm{p}<0.001)$ and pneumococcus $(\mathrm{p}=0.04)$. EMR reminders with panel management significantly improved rates in health care proxy designation $(p=0.02)$ and osteoporosis screening $(p=0.006)$ in comparison to EMR alone. Strengths 
associated with this study include the randomized, controlled study design and well described inclusion and exclusion criteria. Limitations of the study included: a single site at a hospitalbased academic practice reducing the representation of outpatient primary care practice; physician's response to the EMR reminders was at their discretion; and a focus on patients who had not received recommended care at the start of the study. Researchers did not report whether participants had previously declined the practice behavior.

Player et al. (2010) randomized thirteen offices with 53 providers to the intervention of EMR prompts and education, and fourteen offices with 66 providers to the control group, with a total of 67,000 patients. The study's aim was to examine the impact of EMR reminders for the diagnosis and treatment of classical symptoms of gastroesophageal reflux disease (GERD) and atypical symptom GERD. Education was given to intervention providers and their staff prior to implementation of EMR reminder. New diagnosis of GERD increased significantly using the EMR reminder group (3.1\%) compared to the control group (2.3\%) $(\mathrm{p}<0.01)$. After controlling for clustering, the odds of diagnosis in the intervention group were 1.33 (95\% CI 1.13-1.56). For participants with atypical symptoms, those in the intervention group had higher odds of being diagnosed with GERD (OR 2.02, 95\% CI 1.41-2.88) and higher odds of being treated for GERD (OR 1.40, 95\% CI 1.08-1.83) compared to the control group. Strengths of the study include the following: study design of block randomization, well described inclusion and exclusion criteria, and use of national guidelines for diagnosing and treatment of GERD. The study did not include information on whether the participants had been diagnosed or treated by specialists for GERD.

Sequist et al. (2005) enrolled 194 primary care physicians who had 4,549 patients with diabetes and 2,199 patients with coronary artery disease (CAD) in 20 ambulatory clinics in a six month study to evaluate the impact of EMR reminders on diabetes and CAD care based on 
guidelines. Additionally, the authors surveyed the attitudes of the physicians toward the EMR reminders. The clinics were randomized into an EMR reminder intervention group or usual care. All 20 clinics received EMR reminders on preventive medicine services based on recommendation of United States Preventive Services Task Force (USPSTF). The intervention group received additional EMR reminders for diabetes and CAD care. Investigators found that EMR reminders increased the odds of receiving recommended diabetes care (OR 1.30, 95\% CI 1.01-1.67) and CAD care (OR 1.25, 95\% CI 1.01-1.55). The impact on the individual reminders was variable. Findings indicated that the majority of physicians (76\%) thought reminders improved the quality of care. The most common barriers to guideline adherence were found to be lack of familiarity (40\%), lack of awareness (38\%), and forgetting to apply guidelines (26\%). Interestingly, the authors suggested that physician acknowledgement of reminders may be a key to success. Strength of the study was the design. The study design used a stratified randomization for gender and socioeconomic factors and the statistical analyses. A limitation of the study was the use of mailed surveys. The reliance on physician response needed to be documented into EMR for some measures, such as dilated eye examinations. A threat to construct validity was the possibility of a compensatory effect due to the control group receiving information on preventive care services within the EMR system. The authors noted the software for the EMR reminders lacked a direct connection into computerized ordering which may have decreased effectiveness.

Shelley et al. (2011) assessed the impact of EMR with clinical decision support and performance feedback compared with EMR alone on provider adherence to Joint National Committee on Prevention, Detection, Evaluation, and Treatment of High Blood Pressure (JNC 7) guidelines. A quasi-experimental study design with repeated measures was conducted at four 
federally qualified health centers. Providers and staff tailored the clinical decision support system to prompt a blood pressure (BP) alert, a hypertension (HTN) order set, an HTN template, medication adherence forms, and clinical reminders. Two 2-hour training sessions were provided on JNC 7 guidelines and the new EMR features. Clinical staff was trained on using EMR features and their roles in a single 45 minute session. The pre-intervention period was 17 months and the post intervention period was 15 months. The investigators found that the rates of HTN control were significantly greater in the post intervention period ( $50.9 \%$ from baseline to 60.8\%; p < 0.001). Patients were 1.5 times more likely to have controlled BP post-intervention. The authors reported positive findings were related to clinical decision support (CDS) system features. The strengths of the study by Shelley et al (2011) included a well defined inclusion and exclusion criteria. The statistical methods used were qualitative and quantitative. The study design is practical for real clinical settings. Limitations of the study lacked randomization. BP was not observed at distinct time points and not all patients contributed the number of BP measurements therefore creating measurement bias. The authors were unable to separate the effect of the multiple components of the intervention.

Another study that supported Shelley et al. (2011) was conducted by Kawamoto, Houlihan, Balas, and Lobach (2005). This study found a strong association between clinical decision support and positive outcomes. The four features included automatic provision of decision support as part of clinical workflow, provisions of recommendations, point of care decision making, and computer-based support (Kawamoto, Houlihan, Balas, and Lobach, 2005).

Two pre- and post- intervention studies supported the use of EMR reminders. In the study by Hunt et al. (2009) the researchers implemented an EMR reminder that automatically prompted physicians on quality improvement interventions in diabetes outcomes. The physician 
and staff had the autonomy to incorporate the extent of EMR system. The outcomes were based on American Diabetes Association (2004) guidelines. The study enrolled thirteen clinics and 6,072 patients with diabetes. All practitioners and staff were encouraged to attend a 90-minute training session. The EMR features were piloted during a one-year trial to determine best practice workflow. Physicians and staff had the autonomy to implement the system at their discretion. Two years after implementation, goal attainments in low density lipoprotein (LDL) increased significantly from 32\% to 56\% ( $\mathrm{p}=0.02)$, while the mean LDL decreased by thirteen percent $(0.33 \mathrm{mmol} / \mathrm{l}, \mathrm{p}=0.002)$. The assessment of the BP increased significantly from $30 \%$ to $52 \%(p=0.002)$. The coding complexity increased significantly $(p<0.001)$. The strength of this study is the scope to generalize the findings. This study was conducted in community-based clinics of multiple locations with a diverse payer mix. The study included inclusion and exclusion criteria. One weakness of the study was the attrition of the participants over the 24 month study. From the original 6,072 participants, only 2,223 (57\%) were still enrolled at the end of the study. However, new patients were enrolled throughout the study $(n=3,607)$ for a total of 7,456 participants at the end of the study. This may have contributed to state-of-health bias. There were differences between patient characteristics at baseline and follow-up. This bias was minimized by the evaluation process. Participants were included if they were continuously enrolled for primary analysis. A confounding factor was a monetary performance incentive. Clinicians were given up to $\$ 600$ for meeting outcome goals; however, this could have positively affected attrition rates. The question becomes what happens when the monetary incentive is no longer available.

A similar study, also evaluated the impact of EMR implementation, which featured prompts and reminders on diabetes care (O’Connor et al. 2005). A five year longitudinal 
controlled study compared 122 adults with diabetes at an intervention EMR clinic to a control non-EMR clinic. The EMR reminders and prompts were visible on the computer screen but a provider response was not obligatory. Training sessions included formal instruction and one-onone physician support. The study examined the process of care measures to the number of A1C and LDL tests completed. Intermediate outcomes assessed threshold measures A1C and LDL tests in one calendar year. The frequency of the A1C test significantly increased in the EMR clinic compared to the non-EMR clinic $(\mathrm{p}<0.001)$. The study further found A1C tests significantly improved in both clinics $(\mathrm{p}<0.05)$ with no significant differences between the clinics in two years $(p=0.10)$ or in four years $(p=0.27)$ after EMR intervention. Results were similar with LDL findings. Statistical methods were used to control for patient characteristics which adds strength to this study. All biochemical measurements were performed at the same laboratory. Measurement bias was addressed by including only those patients who attended their original clinic during the study period. The threat of information bias needs to be considered due to the length of the study. Another limitation was the small sample size $(n=122)$.

Riley, Galang, and Green (2011) conducted a reversal-design prospective study exploring the effect of EMR reminders on adherence to standards of prenatal care. The sample consisted of 144 prenatal patients at baseline, 115 at intervention, and 169 patients at post-intervention. This descriptive study collected data from two family medicine teaching clinics at baseline, intervention, and post-intervention. Adherence to prenatal care standards by providers was less than optimal at baseline. The participating providers were expected to respond to the EMR reminder to satisfy the patient care request. Post-intervention phase the EMR reminders were no longer active. Overall, the compliance with prenatal care standards significantly increased from 9.5\% to 55.7\% during the intervention phase $(\mathrm{p}<0.001)$, and significantly decreased back to 
17.1\% post-intervention ( $\mathrm{p}<0.001$ ). The study included rural and urban clinics which would increase generalizability. The description of the methods was given in detail. Limitations included: a small sample size and possible Hawthorne effect due to the study facility conducting monthly chart audits. The study did not discuss whether providers deemed the tests necessary or if documentation was adequate for data collection, which may lead to information bias. A study by Shojania et al. (2009) found similar results to Riley Galang, and Green (2011). Shojania et al. (2009) also supported EMR reminders that require a user response have a trend toward a larger improvement in provider behavior to perform a desired action.

\section{Synthesis}

The evidence collected through the evaluation of nine studies including five RCT's (Feldstein et al., 2006; Gill et al., 2009; Loo et al., 2011; Player et al., 2010; Sequist et al., 2005), one quasi-experimental study (Shelley et al., 2011), two pre-post intervention studies (Hunt et al., 2009; O’Connor et al., 2005), and one prospective descriptive study (Riley et al., 2011) suggest that EMR reminders positively affect patient care. All nine studies focused on adherence to guidelines based on national standards. One RCT (Player et al., 2010) focused on identification of diagnosis. Four RCT’s (Feldstein et al., 2006; Gill et al., 2009; Loo et al., 2011; Sequist et al., 2005), two pre-post intervention studies (Hunt et al., 2009; O’Connor et al., 2005), and one prospective descriptive study (Riley et al., 2011) focused on some aspect of screening tests. Four RCT’s (Feldstein et al., 2006; Gill et al., 2009; Player et al., 2010; Sequist et al., 2005), one quasi-experimental study (Shelley et al., 2011), and one pre-post intervention study (Hunt et al., 2009) assessed the impact of EMR reminders on plan of care. Three out of the five RCT’s (Feldstein et al., 2006; Gill et al., 2009; Loo et al., 2011) and two pre-post intervention studies (Hunt et al., 2009; O’Connor et al., 2005) mentioned that a response to satisfy the EMR 
reminder was not obligatory. Two RCT’s (Loo et al., 2011; Player et al., 2010), one quasiexperimental study (Shelley et al., 2011), and two pre-post intervention studies (Hunt et al., 2009; O’Connor et al., 2005) discussed training sessions prior to implementation of EMR reminders.

Differences were noted among the studies in the review of literature. The evidence that EMR reminders improve screening and identification of specific diagnoses was heterogeneous. The likely plausible explanation for heterogeneity in the evidence was varied: length of time during the intervention phase, education methods, outpatient settings, and outcome foci. Two RCT’s (Gill et al., 2009; Sequist et al., 2005) surveyed providers. Both studies indicated that providers view EMR reminders as beneficial. Sequist et al. (2005) further reported that the most common barriers to guideline adherence were time and patient noncompliance as external factors. The survey also provided insight about physicians’ points of view for not using guidelines as lack of familiarity, lack of awareness, and lack of agreement with guideline recommendations. Although this is one study, education must be considered when implementing a practice change that involves adherence to guideline standards.

There are similarities in the evidence of the studies. Each study used national guidelines to underpin the development of the EMR reminders. The projects were interested on provider behavior change. The studies focused on a combination of diagnosing, screening, or initiating plan of care measures.

Provider input is needed on an innovation to maximize efficient workflow. Three RCT’s (Feldstein et al., 2006; Gill et al., 2009; Sequist et al., 2005) and one quasi-experimental study (Shelley et al., 2011) discussed the importance of engaging clinical staff in developing the process of EMR reminders. Two RCT’s (Loo et al., 2011; Sequist et al., 2005) recommended 
that provider acknowledgement of EMR reminder be required to possibly increase usage. Three RCT’s (Feldstein et al., 2006; Gill et al., 2009; Sequist et al., 2005), one quasi-experimental study (Shelley et al., 2011), and one pre-post intervention study (O’Connor et al., 2005) emphasized the importance of implementing an EMR reminder that fits into the existing workflow.

The evidence supports the use of EMR reminders to improve patient care. The findings of this review of literature provide implications to consider when implementing an EMR reminder practice change. Practices are facing an escalating number of patients with prediabetes and diabetes. Primary providers have a vital role in earlier detection and implementing interventions in patients with prediabetes. A seminal study, the Diabetes Prevention Program (DPP) intervention trial found that diet and exercise can lower the incidence of type 2 diabetes by $58 \%$ over three years among those at risk for diabetes (Benjamin, Valdez, Geiss, Rolka, \& Narayan, 2003).

There are gaps in the evidence related to the effects of EMR reminders specifically on the prediabetes population. Further research is needed on the impact of EMR reminders on disease management and outcomes. Shelley et al. (2011) identified the need for the key components of the recommended care process to optimize synergy between the different software systems.

Prevention is the key. Research clearly supports the use of EMR reminders. A practice change incorporating a focused education program and EMR reminders on screening, identification, and plan of care for patients with prediabetes is supported by this review of literature. There is evidence of a relationship between EMR reminders and improved patient care. 


\section{Chapter III: Methodology}

\section{Project}

This proposed project included an educational intervention and implementation of an EMR reminder, followed by an evaluation of a provider behavior change in the screening, identification, and treatment of patients at-risk for prediabetes. An EMR reminder was implemented into the existing software at three facilities of WCHSA. The EMR reminder prompted providers to screen for prediabetes. Knowledge about prediabetes and the EMR reminder process was given during a single group educational session prior to activation. Preand post-intervention chart audits was completed on 100 randomly selected patients to evaluate accuracy in screening, diagnosing, and documenting plans of care for patients with prediabetes. The project was conducted for eight weeks. The proposed project was concluded with dissemination of results to stakeholders.

\section{Setting}

The setting of this project was located in a Federally Qualified Health Care facility located along the western border of WV along the Ohio River. This practice change was supported by the mission statement of WCHSA. The mission statement underpinning the practice is "to improve the health status of our patients and our communities by providing access to quality primary, urgent, and preventive health care regardless of one’s ability to pay” (WCHSA, 2009). WCHSA currently collaborates with Mid Ohio Valley Rural Health Alliance on projects to support a "Change the Future West Virginia” program. This grant program aims at promoting activities of prevention. This proposed capstone project was in congruence with WCHSA organization strategic plans. 


\section{Goals and Objectives}

The ultimate goal of the proposed capstone project was to focus on evaluating the new innovation of adding clinical reminders about prediabetes into the existing EMR. This innovation was adopted to improve the health status of the patient population. Awareness of the magnitude of the diabetes epidemic has heightened the emphasis on prevention. The hypothesis for the capstone project is: A provider focused education program and the use of an electronic medical record (EMR) reminder will improve the screening, identification and treatment plan for patients with prediabetes. Following are the four main objectives for this capstone project:

1. Provider knowledge regarding the recommended screening, diagnosis of and treatment of patients with prediabetes will improve.

2. The proportions of patients who are screened for prediabetes will increase.

3. The proportions of patients diagnosed with prediabetes will increase.

4. A greater percentage of patients who have been diagnosed with prediabetes will receive treatment plan of care.

\section{Project Design}

This capstone project was designed to implement an EMR reminder. The EMR reminder has improved the idea of screening, identifying, and documenting the treatment care plans for patients with prediabetes after provider education and the implementation of an electronic medical record (EMR) reminder. The CEO of WCHSA granted permission to incorporate the EMR reminder into the current software program (Appendix A). The project was based on national guidelines and evidence-based research. The ADA (2012) guideline has identified risk factors for prediabetes and when to initiate screening. The ADA (2012) outlines a brief description of lifestyle modification guidelines for patients identified with prediabetes. 
The proposed project incorporated the EMR reminder to automatically trigger a provider to respond if desired. The EMR reminder was activated when a patient had been diagnosed with known risk factors for prediabetes such as: hypertension, hyperlipidemia, depression, microalburia, polycystic ovary syndrome, overweight or obesity, and tobacco use. Other risk factors identified in the ADA (2012) guideline include: peripheral arterial disease coronary artery disease, stroke, carotid artery stenosis, and aortic abdominal aneurysm. Although these diagnoses are not considered a fully inclusive list for prediabetes screening, the clinical practice guideline was available for each provider to review for additional risk factors. The existing computer system required an ICD-9 code to allow the initiation of the automatic reminder. An analysis of the ICD-9 codes currently utilized was compiled to reflect the known risk factors and maximize the use of the EMR reminder. An EMR reminder called, "Prediabetes/Diabetes Risk” appeared under the "Health" tab in the EMR system (see Appendix G). The "Health" tab was already listed on the EMR toolbar. Providers satisfied the prompt by clicking the "Prediabetes/Diabetes Risk” box on the screen. Attached to the "Prediabetes/Diabetes Risk” check box, laboratory screening tests suggestions was visualized under the “Add to Orders.” The providers had the autonomy to order tests from this section of the EMR to simplify steps. This capstone project provided an EMR prompt to remind providers to identify patients with prediabetes. The timeline for this capstone project consisted of five phases (Appendix B).

The idea of using an automatic EMR reminder to trigger a prediabetes management plan was discussed with key leaders through one-on-one formal conversation with the Chief Executive Officer (CEO), Medical Director, and Clinical Nurse Manager (CNM) to assess the feasibility of the proposed project. The social system in this practice change was WCHSA, a federally qualified health care (FQHC) center in rural WV. 


\section{Phase One}

Phase one began with the design and development of the practice change. The project had been thoroughly explored in formal brainstorming meetings with the Medical Director and the CNM to assess the feasibility of implementing an EMR reminder into the existing software program. In preparation for the Institutional Review Board (IRB) approval, the following tasks were accomplished in phase one: (a) reviewing and synthesizing literature, (b) determining the theoretical framework to scientifically underpin the project proposal, (c) completing the needs assessment, (d) securing capstone site and committee, (e) developing the EMR reminder scripts, (f) developing the staff education plan on prediabetes, which includes a content outline (Appendix C), a power point presentation (Appendix D), and hand-outs (Appendices E \& F), (g) developing the data collection tool (Appendix H), (h) developing the marketing strategy, (i) determining the budget plan (see Appendix I), (j) writing the capstone proposal, (k) obtaining capstone committee approval, (l) completing the CITI training, and (m) accomplishing IRB approval for the capstone project. In addition, during this phase the sample was defined. For the purposes of this project inclusion criteria were: all patients seen at the clinics who are aged 2570 years and who have been seen in the last three years. Those who already had a diagnosis of diabetes were excluded.

\section{Phase Two}

Phase two began after IRB approval. Activities completed during this phase were necessary prior to implementation of the EMR reminder. Congruent with Rogers Diffusion of Innovations Theory, communicating with key stakeholders about the project facilitated support for successful participation in the project. Pre-intervention tasks included: (a) baseline data collection of one hundred randomly selected charts, (b) educational strategies with health care providers, which included announcement of project plans to total WCHSA staff during regular 
monthly meeting, bulletin board displays in each exam room with the Diabetes Risk Test (Appendix J), and lobby bulletin board displayed "The Healthy Plate" and "You Have the Power to Prevent Diabetes” posters; (c) preparation for the set-up of the group education session for clinical staff, which included scheduling a date, securing a conference room, organizing lunch arrangements, coping of hand-outs, reviewing Polycom/TV system set-up, reserving a laptop, reserving a computer and projector; (d) providing group education for three office locations simultaneously through a Polycom/TV system; (e) completion of a trial for the EMR reminder prompts/scripts with test computers; and (f) identification of project champions for each site. The trial of the EMR reminder prompts had occurred in the presence of the project leader.

\section{Phase Three}

Phase three began with activation of the EMR reminder for patients at-risk for prediabetes/diabetes. The project leader communicated on a weekly basis with project champions from all three sites. This was done alternating by telephone conversation and site visits. Daily e-mail access was available daily for trouble-shooting or obtaining feedback. Phase three ended after eight weeks of EMR reminder implementation.

\section{Phases Four and Five}

Phase four involved evaluation of the practice change. During this phase the project leader completed (a) chart audits on randomly selected charts, (b) data analysis, and (c) a final written capstone paper. The project leader prepared a report for stakeholders on the evaluation of the practice change. Phase five brought the capstone project to closure. The highlight of this phase was the presentation of capstone project to the capstone committee. A final report was shared with the CEO of WCHSA. This phase has been a stepping stone for future research and publications. 


\section{Resources}

Resources were identified to assist in the success of this capstone project. To implement a new EMR reminder into the existing software program several resources were needed to accomplish this projects outcome. Resources identified for this project were stakeholders, educational materials, EMR system, data collection tool, and a budget plan. The overall aim of the project was to focus on WCHSA providers from the three family practice offices located in Jackson County and Wirt County, WV.

The primary resource for the project was the project leader. Key stakeholders to support the implementation and practice change were the CEO, project mentor, project champions at each site, CNM, providers, clinical staff, laboratory service, and a pharmaceutical company. Participation in this project did not change the responsibilities of the usual daily patient care. During the design portion of the capstone project, input from the project mentor and the CNM was vital considering their role on the in-house IT team.

Education was needed to provide understanding to users. A formal education session for clinical staff was needed to explain rationale and the process of the EMR reminder practice change. A goal of the project was to influence the behavior of providers to improve their screening, identification, and treatment plan of care for patients at-risk for prediabetes/diabetes. The educational content included (a) the background and significance of prediabetes, (b) the risk factors for prediabetes, (c) recommended testing for prediabetes, (d) the treatment recommendations for patients with prediabetes, and (e) the EMR reminder process. Information, such as research studies, websites, algorithms, risk tests, and guidelines was offered to be emailed or printed for those who desire additional reading material. The educational component was delivered live with use of an existing Polycom/TV system to communicate content simultaneously to all three offices. This instruction was provided during the noon hour for a 
thirty minute power point presentation (Appendix D). Hand-outs offered to participate were a reference list supporting educational content (Appendix E), and “Algorithm: Pre-Diabetes Identification and Intervention" (Appendix F). Attendance sheets recorded those who were present and assisted in identifying those who were absent (Appendix K). A pharmaceutical company was recruited to sponsor lunch to encourage attendance. The space used for the educational offering was at each site's conference room.

The EMR system used at WCHSA has been in place for the past two years. Training was centered on the use of the new EMR reminder for prompting prediabetes screening. This instruction was part of the education session by the project leader. Building the foundation of application knowledge about prediabetes promotes clear understanding of the rationale supporting the intervention of EMR reminders. A formal education program was scheduled for clinical staff and providers to deepen the understanding of the importance of screening and identifying patients with prediabetes. Handwritten guidelines were available to providers for review along with appropriate websites.

Laboratory services exist within each office setting; therefore, testing for prediabetes was readily available to confirm diagnosis. Lab Corp services provided venipuncture supplies for appropriate testing. Tests results were forwarded to each patient's primary provider for further review and updating of the patient's problem list with proper ICD-9 code.

The data collection tool was designed by the project leader to assist with pre- and postintervention chart audits (Appendix H). The tool was based on the ADA (2012) Standard of Medical Care in Diabetes guidelines and supporting evidence from the literature with emphasis on risk factors for prediabetes. The ADA (2012) has proposed major risk factors for type 2 diabetes. These guidelines were created for early detection in individuals at-risk for diabetes; 
therefore the same criteria were used for prediabetes. Screening should begin at age 45 years of age in the absence of other risk factors. Screening should be considered in all adults who are overweight $\left(\mathrm{BMI} \geq 25 \mathrm{~kg} / \mathrm{m}^{2}\right)$ and have physical inactivity, first-degree relative with diabetes, high risk ethnicity, history of gestational diabetes, women who delivered a baby greater than nine pounds, history of cardiovascular disease, hypertension (B/P $\geq 140 / 90)$, dyslipidemia (HDL $<35$ $\mathrm{mg} / \mathrm{dl}$ or triglycerides $>250 \mathrm{mg} / \mathrm{dl}$ ), or women diagnosed with polycystic ovarian syndrome (PCOS) despite age (ADA, 2012). The data collection tool included demographic information. The data collected included gender, age, vital signs, and labs (fasting or random). No identifying data such as name, address, date of birth or social security number was collected. The most recent laboratory results were recorded. These results included: glucose, hemoglobin A1C, total cholesterol (Chol), high density lipoproteins (HDL), triglycerides (Trig) and low density lipoproteins (LDL). Most recent vital signs included blood pressure (B/P), weight (Wt), and body mass index (BMI). The data collection tool was also recorded data on whether screening was warranted, evidence of screening for prediabetes, evidence of a diagnosis of prediabetes, and evidence of a treatment plan for prediabetes.

\section{Budget Plan}

A budget plan was devised to guide this evaluation of an EMR reminder practice change project (Appendix I). The estimated cost of this project is $\$ 2,958.07$ based on information received from the WCHSA human resource department, local gas prices, Office Depot, and WalMart. The cost of the equipment, copies, and staff participation was considered an "in-kind" donation from WCHSA. The space provided for the project, announcement, clinical education session, and practice change activities that occurred during regular business hours of WCHSA. The remaining costs of the project were the Project Leader's travel expenses and time. The other 
expense was the amount of time the Project Mentor invested in the preparation and coordination between the computer software and the practice change of an EMR reminder. The Project Mentor had verbally committed his time as donation since this project will assist in future projects and grant opportunities.

\section{Key Site Support}

Support for an EMR reminder which prompts providers to explore patients at risk for prediabetes at WCHSA had been an ongoing discussion while conducting the needs assessment and determining feasibility. The CEO had given support to the Project Leader's participation in the DNP program at WVU. The integration of this EMR reminder fitted into the existing system and did not interrupt activities with office flow. A letter of support had been obtained from the CEO of WCHSA (Appendix A).

\section{Planned Evaluation}

The evaluation phase followed the completion of the EMR reminder intervention. The accessible population for this evaluation was adults' age 25 years and older who were established patients at a federally qualified health center (FQHC) which is located in Jackson and Wirt County, WV. The first component of the evaluation phase was to compare the pre-intervention and post-intervention chart audits using the data collection tool. A random selection of 100 preintervention charts from the practice cohort was reviewed. Eligible charts for this review only included for those of patients aged 25-70 years who have been seen within the last 3 years. Charts of patients with a known history of diabetes were excluded. A random selection of 100 charts from the intervention period was also reviewed using the same inclusion and exclusion criteria. Demographic data included the patient's gender, race, and age. Descriptive statistics were used to compare the demographic data of pre-intervention and post-intervention groups. 
Laboratory variables included glucose (fasting or random), hemoglobin A1C, Chol, HDL, Trig, and LDL. Vital signs reviewed were B/P, Wt, and BMI. Each chart was audited on questions pertaining to evidence of identification of prediabetes, screening, and treatment plan (Appendix $\mathrm{H})$. The continuous variables and questions were evaluated by comparing the pre- and postintervention data by chi square. The statistical software SPSS 20 was used to analyze the data.

\section{Chapter IV: Results}

\section{Sample Characteristics}

The target sample for this project was a diverse group of medical providers. The group of providers had different education backgrounds which included: four medical doctors, one doctor of osteopathic medicine, four nurse practitioners with master's degrees and two pursuing their doctorate of nursing practice, and one physician assistant. During the intervention period only one medical student and one nurse practitioner student were on site for the project. The genders of the providers including the students were four males and eight females.

\section{Evaluation}

The four project objectives were evaluated after data was collected from the postintervention period (August 8, 2012 to October 3, 2012). The foundation for each objective was supported by a single educational session offered on August 7, 2012 as well as the EMR reminder. This session occurred prior to the activation of the EMR reminder. Content on prediabetes and the EMR reminder process was given live by a Polycom TV system for all sites concurrently. The session included a power point presentation and educational materials were available. Informed consent forms from the participants were obtained. Five out of ten providers were present, one physician, three nurse practitioners, one physician assistant, as well as one medical student. All three project champions were in attendance and verbalized understanding 
of the proposal and their role in the project. Those not present were given the information oneon-one with Project Leader or project champions. Confirmation of their understanding was completed by Project Leader and informed consent was then obtained.

The evaluation phase of the project began after an eight week intervention period. The computer system was unable to differentiate established versus acute care only patients. Therefore, the 100 randomly selected charts had the potential to include both established and acute care only patients.

Data was collected from multiple tabs within the EMR system. The information was retrieved from tabs labeled: problem list, medication sheet, vital signs, documents, lab results, images, tasks, and orders. For each chart audit, three demographic, eleven vital signs/lab, nine questions, and fourteen risk factors were reviewed on patients at risk for prediabetes.

Specific risk factors for prediabetes were also collected. The risk factors were HTN, CVD, Overweight/Obesity, PCOS, HDL less 35, triglycerides greater than 250, family health history, smoking, race, sedentary lifestyle, depression, gestational diabetes history, and history of delivering babies greater than nine pounds. The additional risk factors were collected to add substance to the importance of the health care problem surrounding prediabetes. The risk factors were based on the ADA (2012) guidelines. Depression is not mentioned in the ADA (2012) guideline but is present in research studies. A meta-analysis was conducted on depression as a risk factor for the onset of type 2 diabetes. Knol et al. (2006) concluded that non-diabetic adults with depression have a 37\% increase risk for type 2 diabetes.

The DCT had written questions to be evaluated. The questions that were assessed included: does the patient qualify for screening, was the patient screened for prediabetes, is there evidence to support a prediabetes diagnosis, was patient diagnosed with prediabetes, and is there 
evidence of a treatment plan. Treatment plan was further assessed specifically for: follow-up labs ordered, lifestyle change, referral to dietitian, and medications for prediabetes. The same information was collected for both pre- and post-intervention chart audits. The statistical software used for the data analysis was SPSS 20. Results were reviewed by project leader and evaluation team. The capstone chair and committee, Project Leader, Project Mentor, and consulting statistician served as the evaluation team. Chi-Square analysis was used to compare the baseline and post-intervention data and the threshold for statistical significance was set at 0.05 .

\section{Project Results}

The purpose of this project was to determine if a provider focused education session and an EMR reminder would improve screening, identification, and documentation of a treatment plan of those patients at risk for prediabetes in a rural health care setting. Each chart $(n=189)$ met the criteria to qualify for screening of prediabetes from risk factor analysis. Excluding the students, the provider education session had 50\% participation from employed providers.

There are two samples that are described in this project, baseline and post- intervention. The baseline sample consisted of 100 randomly selected charts from the practice cohort. The pre-intervention chart audits totaled 97 for evaluation. Three charts were excluded, one had type 2 diabetes and two were not established patients and seen for acute care visits only. The baseline sample $(n=97)$ had a mean age of 48 with standard deviation (SD) of 12.213 years. The minimum age was 26 years and the maximum age was 70 years. The gender distribution in the baseline sample was $41 \%$ male and $56 \%$ female.

Post intervention charts totaled 92. Eight charts were excluded, two had type 2 diabetes and six were not established patients and seen for acute care visits only. The post intervention 
sample $(n=92)$ had a mean age of 50 years with a standard deviation of 11.592 years. There were $33.3 \%$ males and $62.5 \%$ females in the post intervention sample. Race/ethnicity was not analyzed because both pre- and post-intervention sample was $99.4 \%$ Caucasian $(n=188)$ and $.53 \%$ Latino $(n=1)$. This is consistent with the racial statistics of Jackson and Wirt County. Specific criteria were tracked using the data collection tool (DCT). This criterion was used to determine patient risk factors for prediabetes. One measure used was BMI. The ADA (2012) guidelines indicate that patients with a BMI greater than 25 plus one other risk factor should be screened for prediabetes. The average BMI in the baseline sample was 33 (SD= 7.5296) and post intervention $33(\mathrm{SD}=6.2671)$. One-hundred percent of the entire data sample (baseline and post intervention) was classified as overweight/obese (BMI > 25).

Evaluation of combined data set (baseline and post-intervention) noted hypertension (B/P greater than 140/90) or diagnosed with hypertension at 59.8\%. The most recent blood pressure documented was collected from each chart. Hyperlipidemia is another risk factor for prediabetes was also reviewed. The sample revealed 39.9\% had the diagnosis of hyperlipidemia. Triglycerides greater than $250 \mathrm{mg} / \mathrm{dl}$, another risk factor for prediabetes was found to be $8.0 \%$ and HDL less than 35mg/dl was $12.2 \%$ of the combined sample. Missing data from chart audits was marked unknown, noting 33.5\% of lipid values were unknown. Positive family history among the sample was 31.7\%. The percentage of unknown documented family history was $9 \%$. Smoking as a risk factor was noted at $46.0 \%$ of the combined sample. Depression was reviewed and found $24.3 \%$ of the combined sample had been diagnosed. No charts had documentation of microalbuminuria. 
Objective 1. Provider knowledge regarding the recommended screening, diagnosis, of and treatment of patients with prediabetes will improve. An assumption was made that this objective was met from the results of the objectives 2-4.

Objective 2. The proportions of the patients who are screened for prediabetes will increase. This objective was met. This project supported evidence that the intervention worked to improve screening practices among the providers. Screening was based on glucose or A1C lab values. No OGTT were ordered or documented in the chart audits. Pre-intervention labs were reviewed from August, 2010 to August 7, 2012. Post-intervention labs were taken from the eight week intervention period. Lab values were also retrieved from provider reviewed old medical charts, if available, and outpatient lab results that were scanned into the image section of the EMR. Abnormal lab value was determined as per ADA (2012) guidelines. Screening on the DCT was marked "yes” if the patient had a normal lab value (glucose or A1C) listed within the time frame of the study. If the chart indicated one abnormal test and a confirmation test was ordered or pending, the finding was counted as “yes” for the screening question. If no laboratory values (glucose or A1C) were documented, the question was marked “unknown.” The question was marked "no” if the chart did not have appropriate lab screening for prediabetes during annual exam and had documented risk factors. The search for the laboratory information was reviewed from progress/message note or order tab. The presence of laboratory values and labs ordered by providers does not guarantee that screening was advised by provider for the sake of prediabetes. The post-intervention chart audit revealed that follow-up lab orders by providers was statistically significant $(\mathrm{p}=0.0001)$. The number of patients who were eligible to be screened for prediabetes was reviewed in order to calculate the proportions that were screened in both the baseline and post-intervention samples. Of the patients studied $100 \%$ qualified to be 
screened. In the baseline sample 31 were screened out of 97 in the sample. In the postintervention sample 83 were screened out of 92 in the sample. Chi-square analysis showed that this was statistically significant $(\mathrm{p}<0.0001)$. Although not a focus of this project, postintervention chart audits revealed that in a few cases providers documented conversation with patients that indicated the possibility of prediabetes.

Objective 3. The proportions of patients diagnosed with prediabetes will increase. This objective was met. There was an increase in the number of patients who were correctly diagnosed with prediabetes after the intervention. One question on the DCT asked if there were evidence to support a prediabetes diagnosis. The charts were reviewed using the ADA (2012) criteria for the diagnosis of prediabetes. Baseline chart audit indicated 21 charts had evidence to support the diagnosis of prediabetes. Three patients were initially found to have a diagnosis but two were misdiagnosed and did not have evidence to support the diagnosis. Only one patient in the baseline sample who had evidence to support diagnosis was correctly diagnosed. Postintervention data indicated 22 out of 92 had evidence to support the diagnosis of prediabetes. Of those, eight were correctly diagnosed. No misdiagnosed prediabetes was noted in the postintervention sample. ICD-9 codes used for prediabetes include: 790.29, 790.22, and 790.21. The question was marked “yes” if prediabetes was listed on problem list or documented in progress note. Chi-square analysis showed that there was a statistically significant increase in the number of patients diagnosed after the intervention $(\mathrm{p}=0.013)$. Although, statistically significant improvement was found, only $36 \%$ of the patients who qualified for a diagnosis of prediabetes had a diagnosis documented.

Objective 4. A greater percentage of patients who have been diagnosed with prediabetes will receive a treatment plan of care. This objective was partially met. The last objective 
pertained to a documented treatment plan. This objective was originally written to evaluate an increase in percentage of patients with prediabetes would have a documented treatment plan. The question posed to evaluate this objective was: is there evidence of a treatment plan? This question was answered “yes” if follow-up labs were ordered, documented lifestyle changes (diet recommendation or physical activity), referral to dietitian, or medication prescribed for prediabetes. The charts reviewed had multiple risk factors mixed with varied number of diagnoses. A documented treatment plan does not necessarily indicate advice for prediabetes. A treatment plan with similar recommendations for lifestyle modifications may have been prescribed for conditions, such as HTN, obesity, or hyperlipidemia. This realization of a broad treatment plan further clouds the analysis. The EMR templates are set up with generic statements to document patient education on lifestyle changes for diet modification and exercise recommendations. The question was marked “yes” if these statements were checked. Follow-up lab orders were the only specific treatment modality that was statistically improved in postintervention sample ( $\mathrm{p}<0.0001)$. The other treatments, lifestyle changes, referral to dietitian, or prescribed medication were not statistically significant. The treatment, referral to dietitian was not used. While the chi-square analysis for “treatment plan” was not statistically significant $(p=0.509)$, it is of note that $100 \%$ of the patients, in both samples, who had a diagnosis of prediabetes had a documented treatment plan.

\section{Chapter V: Summary, Discussion, and Implications}

\section{Congruence with the Theoretical Framework}

One element of diffusion is the innovation. An innovation is an idea, practice, or object that is perceived as new by an individual or group of adopters (Rogers, 1995). An individual's perception of an innovation is a key feature of Rogers Diffusion of Innovations Theory. The 
innovation for this practice change is implementation of an EMR reminder for prediabetes identification and management.

Communication is one of the four key elements of this theory. Communication is the process through which individuals create and share information to gain a mutual understanding. Most individuals may not evaluate a new idea based on research evidence but on peers’ subjective evaluation to accept or reject the innovation. Educational opportunities will open the door to identify barriers and facilitators of change promoting compatibility. Education was provided through in-house mass email, group sessions, and individual follow-up.

Communicating results of chart reviews pre- and post-intervention has fostered observability for the social system. This information was disseminated during staff meetings, monthly postings, and will be considered for future publications. Other sources of communication included inhouse email, prediabetes risk factors posted on bulletin boards in exam rooms, and one-on-one conversation to further promote application knowledge.

Early and widespread involvement of staff at all levels was needed to enhance success. Champions are important to influence those who are later adopters. Key players were identified through informal conversation and during group educational meetings. The new idea was further explained during a monthly staff meeting by sharing information on prediabetes including incidence, prevalence, and risk factors. This information enhanced knowledge awareness. For staff and new clinical students who were unable to attend the educational session, the information was communicated by email, followed by brief conversations. Printed handouts were available for those who do not prefer to receive email. Champions were used to encourage use of EMR reminder process, answer questions about the practice change, and served as a liaison between staff and Project Leader. 
Data was presented on pre-intervention chart reviews to heighten the awareness knowledge and blend the step of persuasion. The persuasion step is described as individuals forming positive or negative attitudes toward the innovation (Rogers, 1995). Champions were recruited to participate in the development of the application of how the innovation would function. Capitalizing on those who were experts with the computer system was an important asset to this project. Studies support the importance of a seamless innovation that fits into the routine of workflow (Carlfjord, Lindberg, Bendtsen, Nilsen, \& Andersson, 2010; Scott, Plotnikoff, Karunamuni, Bize, \& Rodgers, 2008; Saleem et al., 2005). The existing computer system had the capability to add EMR reminders that prompted providers to initiate patient treatment plans. The innovation was offered on test computers to allow those individuals who were interested to trial the EMR reminder. New innovations require invested time, energy, and resources, therefore trial runs provide opportunities to simplify the process.

Knowledge was gained by targeting learning of a new innovation through a variety of teaching activities. Some individuals learn through a mixture of visual, auditory, or tactile activities. The pilot project also had lent itself to trialability. Piloting the process facilitated understanding through hands-on activities and feedback. A trial of actually using the test computer in a non-threatening environment where patient charts were not affected allowed questions to be generated about the EMR reminder process.

The social system is another element in this theory. Rogers Diffusion of Innovation Theory demonstrates a decision making process in a social system follows an S-Curve. The social system in this project was WCHSA family practice facilities. The S-Curve explains the adoption of a change. Adoption begins with a slow change, followed by a rapid change and ends with slow change as the innovation matures. The new idea diffuses through the social system 
over time. Time is one of the four elements. Rogers believes that as the innovation grows over time, a slowing period will develop prior to formal adoption.

\section{Discussion}

The purpose of this capstone project was to evaluate an EMR reminder on the screening, identification, and documentation of treatment plans on patients at-risk for prediabetes by healthcare providers. Communication is important for the success of a project. The educational session was completed the day before activation of the EMR reminder. Throughout the eight week period contact was primarily initiated by Project Leader. One email was received which pertained to informed consent form. Weekly contact by either phone calls to project champions or site visits did not produce concerns or additional questions regarding the EMR reminder process. Limited response could have been attributed to the EMR reminder fitting into existing system without interruption of typical workflow. Also, this prompt was added to a system which was already familiar to clinical staff.

No statistical significance was noted for a greater percentage of treatment plan documentation from pre-intervention to post-intervention evaluation. Additional handouts or references regarding prediabetes content were not requested. Two of the three sites were considered short of staff due to provider turnover. During the site visit, one provider commented that prevention measures were on hold due to lack of staff and overflowing work schedules. Proper diagnosing of prediabetes would typically influence the treatment plan outcome. Extending the intervention period to three or six months would be helpful to fully evaluate the treatment plan portion of the evaluation.

This project was the first formal evaluation of a practice change at WCHSA. The challenges during this project centered on technical difficulties to evaluate the innovation. These 
technical difficulties pertained to retrieving accurate data to evaluate the objectives properly. This project will serve as a foundation to resolve barriers and overcome limitations for future evaluation projects.

\section{Barriers}

The first barrier was receiving computer generated, pre-intervention data in a timely manner. The delay of receiving data reports was contributed to IT skills of in-house staff. The computer software used during this project was relatively new with installation completed in August, 2010. With computer updates, in-house staff was unable to generate diagnoses productivity reports. This project requested particular criteria to start the random chart selection. The skill level needed to generate practical analytics was referred to the IT consultant. The IT consultant primary role and responsibilities are to the CEO. Access to the IT consultant from the Project Leader was limited. The outside IT consultant charges per hour for his services. This cost was an unexpected. At the same time, our CEO had mandated reports due to the federally system. The priority was to assist the CEO and work on the proposal data was at the convenience of the IT consultant. The ability to retrieve in-house reports rests on the skills of the trained personnel. The pre-intervention data base query was received after six weeks of multiple emails and phone calls. To overcome limited knowledge in retrieving diagnoses productivity reports, further training is needed to increase in-house staff skills. This barrier of the time component increases my awareness of others needs and accountability of my own time and skills. Although the CEO had "buy-in" with the project, the operation of the business was foremost.

Once the pre-intervention data was received, the next hurdle was accuracy in the data. Discovering inaccurate data from computer generated reports from the previous year's created 
chaos. Inaccurate data sets compromised the integrity of the project unless a solution could be found. Reports for day-to-day operations or for projects need to be reliable. Verbalizing that the reports generated did not make sense created frustration for the Project Leader, CEO, and IT consultant. The new computer software utilized outdated coding to produce accurate information. Changes in parameters were needed to assist the CEO and IT consultant to understand the nature of this problem. The original criteria for chart audits could not be used due to the computer limitations. The project parameters were changed to accommodate the computer capacity. The new parameters included: BMI greater than 25 and no diagnosis of diabetes with ICD-9 codes of 250.0, 250.01, 250.02, and 250.03. The time frame was extended from using only eight week period one year prior to onset date on the current software implementation, August, 2010. The charts were reviewed by Project Leader adjusted for specific site and age parameters. The technology of computers should be able to provide reports in a timely manner. The approach of requesting parameter "by hand" is archaic. Retrieving the data in this fashion opened the realization of the computer software barrier to administration. After completion of parameter selection, a 100 randomly selected chart were audited based on the revised DCT. Effective communication was needed to convey systematic computer issues. Communication was completed by email, phone, and face to face contact between Project Leader, IT and the CEO helped find solutions to this system barrier. An outcome of this project stresses the importance of collaborative relationships to define the system problem and communicate to proper administration. Had a solution not been found in manually making computer adjustments, the integrity of the reports would be compromised. Working together with key stakeholders to find a temporary solution allowed the project to move forward. 
Another challenge in collecting information during chart audit was locating specific data within the EMR charts. Chart auditing opens the door for future opportunities on education about documentation. Some charts had no problem list; no family history, no ordered labs, or lab data listed current or in scanned images. The templates have the capability of selecting "No Active Problems,” ordering future labs, and a family health history section which allows for "Healthy" or the documentation of "Reviewed" to be chosen. Encouragement on the importance of documentation should have been part of the initial education outline. Another aspect that was consistently missing was the documentation of the history of gestational diabetes or women who delivered greater than nine pound babies when appropriate. An outcome of this project was the discussion of improving ways to assists providers to document risk factors more easily. This computer software has the capability of making adjustments to standard templates. Adding gestational diabetes and delivering babies greater than nine pounds was suggested to be included in the "GYN" history section.

\section{Limitations}

The national guidelines do not specify the timing of the second confirmation test to diagnose prediabetes. One of the main limitations to this study was the time frame of the intervention period. Increasing the intervention period to 3-6 months is needed. Extending the intervention period allows the potential time to show a statistical difference in diagnosis and therefore, a treatment plan for those with prediabetes.

Another limitation was the capability of the existing computer system. WCHSA is an organization that accepts patient from other established practices for urgent care or for employment physicals only. The computer system was unable to exclude acute care, urgent care, or employment only from data sets. The computer software could not identify risk factors that 
did not have an associated ICD-9 code in order to trigger EMR reminder. Those risk factors had to be reviewed by Project Leader by hand. Another problem with limited computer capability was being able to accurately pull charts based on age and no risk factors. The ADA (2012) guideline indicate that anyone 45 years and older, absence of risk factors should be screened for prediabetes.

A Hawthorne effect would have needed to be considered if this project was a research study. One of the three sites was the home office of the project leader. The presence of the Project Leader is part of the reality of practicing within a health care system. The findings were statistically significant in improving screening and diagnosis of prediabetes. The study was not designed to differentiate which site location contributed to the outcomes of the chart audits. The Project Leader was a full-time employee working beside two other full-time providers (MD and NP). Co-workers may have the tendency to practice differently to please the person in charge of a particular project. Casual conversation may be more prominent in day-to-day operations regarding the project, therefore, influencing attention to project outcomes. The influence of the Project Leader may work in the favor of desired project outcomes.

Another threat to the validity of this project was the Project Leader's participation in the project. The Project Leader's charts had the potential to be chosen both pre-and postintervention. The Project Leader could influence outcome in both data collection sets. The preintervention data could be tainted knowing that the Project Leader was well versed in the area of prediabetes; therefore those charts would be well documented. Future studies may exclude the Project Leader's patients for a more accurate picture of the provider focused education and EMR reminder influence on behavior change.

Implications for Practice. The mission statement of WCHSA states, "To improve 
health status of our patients and our community by providing access to quality health care regardless of ability to pay.” Two years ago, WCHSA implemented an EMR. The EMR system has the capability to make changes in templates to improve patient care/outcomes. One of the current strategic plan goals is to improve health care centered on chronic disease management. Our facility has received a grant to improve diabetes care with emphasis on prevention. The results of this study has influence the continuance of the EMR reminder for prediabetes risk.

This project served to improve screening, identification, and documentation of treatment plans for patients with prediabetes. The proposed plan used established evidence-based clinical guidelines to identify prediabetes to challenge healthcare providers to recognize IFG, IGT, and at-risk hemoglobin A1C results for earlier detection and prevention. Educating the clinical staff on prediabetes has heightened awareness about the significance of earlier detection through screening, identifying, and implementing treatment plan of care. A position statement of the prevention and care of diabetes has been established. These standards of care are to encourage evidence-based care to improve quality of patient care. Guidelines are established for best practice in delivering patient-centered care. Following evidence-based standards will help initiate efforts to reduce financial burden in the future through health promotion and prevention of chronic conditions. Evidence-based recommendations that are implemented as part of routine clinical practice can improve health outcomes and reduce disparities for chronic conditions such as diabetes and heart disease. Bridging the gap between diagnoses and informing patients of their risks with information on lifestyle changes can reduce the burden of health complications and improve quality of life. Findings will be shared with the participating facilities. The facilities can determine other strategies and interventions for patients with prediabetes. 
The findings of this project will be shared with other practices and state agencies that focus on diabetes prevention. Attention will be given to the challenges identified in this project to help others in the process of overcoming systematic problems. The greater picture is diabetes prevention. Providers need to be aware that prediabetes is a health condition. The health care system needs to find ways to ensure proper screening, identification, and management of prediabetes so type 2 diabetes can be prevented. This project clearly identified that education and an EMR reminder statistically supports efforts to better screen and identify prediabetes. Educating our communities and health care decision makers on prediabetes can impact the future health of this country at the national, state, and county level.

Implication for DNP Practice. According to the ADA (2012), prediabetes is a category of increase risk for diabetes type 2, a chronic health condition. Long-term effects of chronic disease can affect vital organs through multiple complications. Prevention is the key to support health. Melnyk and Fineout-Overholt (2011) explains the core competencies for healthcare to meet the needs of $21^{\text {st }}$ century are as follows: provide patient-centered care, work in interdisciplinary teams, employ EBP, apply quality improvement, and utilize informatics. These competencies require a solid knowledge of specialize focus and leadership.

The American College of Nursing (AACN, 2006) published a report on advanced nursing practice. The ACCN task force established quality indicators for advanced nursing practice in a report called, The Essentials of Doctoral Education for Advanced Nursing Practice. The quality indicators promote the foundation of core competencies in leadership and scientific inquiry.

This evaluation project incorporated the DNP essentials. This project was scientifically underpinned using evidence-based research to assist in advancing strategies to ameliorate a health care issue. This capstone project focused on increasing awareness of patient at risk and 
the identification of prediabetes to assist in closing the gap of under-reporting, under-diagnosing, and under-treating. This project promoted collaboration of working within the organizational system. Discovering the computer reporting problem at WCHSA will assist in evaluating future health care concerns. This discovery promotes accountability of accurate data therefore, affecting future project on patient safety. Identifying patients who need to be diagnosed with prediabetes will serve as bases for implementation of a risk reduction program based on clinical guidelines and evidenced-based research. Integrating new knowledge into practice takes leadership to shape healthcare outcomes. Using information system/technology was the bases for this project to evaluate patient care through a provider change in practice. Developing collaborative relationships with key stakeholders will foster the continual support to solve mutual healthcare problems. The report mentioned that the foundation of advanced nursing practice clinical prevention and population health. Following the evidence-based standards will promote healthy outcomes, therefore impacting efforts to reduce financial burden in the future through health promotion and prevention of chronic conditions.

\section{Recommendations}

Further work is needed in collaboration with the providers at WCHSA to sustain provider behavior change in the area of prediabetes. Encouraging open communication with key stakeholders is needed to improve computer software limitations. Revising existing templates to incorporate easy to find risk factors for prediabetes will assess the providers in the assessment to screen for prediabetes. Continuing education on national guidelines and evidence-based research on prediabetes will help in the fight to prevent type 2 diabetes. Finally, feedback on changes needs to be addressed on regular bases. 
This project lays the ground work for future projects in the area of prediabetes. This project supports education sessions for providers. One recommendation would be to add a preand post-test for providers to assess knowledge on prediabetes. The education session should review documentation and where components of the intervention can be found within the EMR. A second recommendation would be to extend the time period for the intervention. Increasing the time frame may provide data to assess for sustainability over time. A third recommendation is to use project champions as liaisons to the Project Leader. Project champions were beneficial in having a person available on-site to answer questions or trouble shoots with the Project Leader. A fourth recommendation would be to exclude the Project Leader's participation in the study. Although this project used random chart selection, the influence of the Project Leader's interest in the topic may affect statistical significance.

The results of this project suggest a synergistic effect on improving a provider behavior change when education and use of technology are used together. The strategic tools of a provider focused education session and implementation of an EMR reminder specifically designed for a health issue has been shown to improve screening, identifying, and documenting a treatment plan. This project can be duplicated with other medical diagnoses and populations. Medical groups considering EMR systems need to carefully evaluate the sophistication of the EMR functions to support workflow of complex medical management of patients. Future projects of combining education and an EMR reminder should be extended to other geographic locations. Further studies are needed to substantiate the results of this evaluation project. The findings from this project can stimulate interest to replicate the findings and encourage research in the area of adults with prediabetes and different approaches to better screen, identify, and document treatment plan. 


\section{Conclusion}

The definition of prediabetes became widespread in 2005 using IFG or IGT measures. However, the parameters have changed over the years. Different organizations have not uniformly use the same numerical values. The recommendations from ADA (2012) clearly define parameters for identifying prediabetes. Prediabetes remains under screened, under diagnosed, and under treated which can lead to missed opportunities for healthcare providers to prevent or delay the progression of type 2 diabetes. The challenge to change provider behavior is to first provide updated information. The findings from this project supported improved screening and diagnosis of prediabetes in provider behavior change. Further research is needed to evaluate sustained provider behavior change with screening and identification for patients at risk for prediabetes. The evidence supported the use of EMR reminders. This capstone project has laid the ground work for future research on evaluating information systems/technology and clinical practices to improve screening, diagnosing, and documenting treatment of patients who are at risk for prediabetes. Diabetes is an epidemic and will overcome economic resources. Health care cost for treating diabetes and chronic complications places a strain on budgets of families, employers, community, and government (United Health Care Group, 2010). A crucial piece, screening, must be implemented to impact prevention of diabetes, recognition, identification, and early intervention. 


\section{References}

Agency for Healthcare Research and Quality (2005). Diagnosis, prognosis, and treatment of impaired fasting glucose tolerance and impaired fasting glucose. Summary, Evidence Report /Technology Assessment No. 128. (AHRQ Pub. No 05-E026-1). Retrieved from www.ahrq.gov

American Association of Colleges of Nursing (2006). The Essentials of Doctoral Education for Advanced Nursing Practice. Washington DC; AACN

American Diabetes Association. (2012). Standards of medical care in diabetes-2012. Retrieved from http://care.diabetesjournals.org/content/35/Supplement_1S11

American Diabetes Association. (2008). Economic cost of diabetes in the U.S. in 2007. Diabetes Care, 31, 596-615. doi: 10.2337/dc08-9017

Benjamin, S., Valdez, R., Geiss, L., Rolka ,D., \& Narayan, K. (2003). Estimated number of adults with prediabetes in the U.S. in 2000. Diabetes Care, 26, 645-649. doi: $10.2337 /$ diacare.26.3.645

Bureau for Public Health, Health Statistic Center (2009). The burden of diabetes in West Virginia 2009. Retrieved from www.wvdiabetes.org/Portals/12/Diabetes_ Burden_FINAL_20100421withcover.pdf

Carlfjord, S., Lindberg, M., Bendtsen, P., Nilsen, P., \& Andersson, A. (2010). Key factors in primary health care: A qualitative study based on implementation theory. BMC Family

Center for Disease Control and Prevention. National diabetes fact sheet: national Estimates and general information on diabetes and prediabetes in United States (2011). Atlanta, GA: U.S. Department of Health and Human Service, Center for Disease Control and Prevention, 2011. 
Diabetes Prevention Program Research Group. (2009). 10-year follow-up of diabetes incidence and weight loss in the Diabetes Prevention Program Outcomes Study. Lancet, 374, 1677-1686. doi: 10.1016/S0140-6736(09)61457-4

Diabetes Prevention Program Research Group. (2002). Reduction in the incidence of type 2 diabetes with lifestyle intervention or metformin. The New England Journal of Medicine, (346), 393-403. doi: 10.1056/NEJMoa012512

Feldstein, A., Elmer, P., Smith, D., Herson, M., Orwoll, E., ...Swain, M. (2006). Electronic medical record reminder improves osteoporosis management after a fracture: A randomized, control trial. Journal of American Geriatric Society, 54, 450-457. doi:10.1111/j.1532-5415.2005.00618.x

Gill, J., Chen, Y., Glutting, J., Diamond, J., \& Lieberman, M. (2009). Impact of decision support in electronic records on lipid management in primary care. Population Health Management, 12, 221-226. doi: 10.1089/pop.2009.0003

Hader, J., White, R., Lewis, S., Foreman, J., McDonald, P., \& Thompson, L. (2007). Doctors' view of clinical practice guidelines: A qualitative exploration using innovation theory. Journal of Evaluation in Clinical Practices, 13, 601-606. doi: 10.1111/j.13652753.2007.00856.x

Hunt, J., Siemienczuk, J., Gillanders, W., LeBlanc, B., Rozenfeld, Y., Bonin, K., \& Pape, G. (2009). The impact of a physician-directed health information technology system on diabetes outcomes in primary care: a pre-and -post implementation study. Informatics in Primary Care, 17, 165-174.

Kawamoto, K., Houlihan, C., Balas, A., \& Lobach, D. (2005). Improving clinical practice using clinical decision support systems: A systematic review of trials to identify 
features critical to success. British Medical Journal, 330, 765-768.

doi:10.1136/bmj.38398.500764.8F

Knol, M.J., Twisk, J.W.R., Beekman, A.T.F., Heine, R.J., Snoek, F.J., \& Pouwer, F. (2006).

Depression as a risk factor for the onset of type 2 diabetes mellitus. A meta-analysis.

Diabetologia, 49, 837-845. doi:10.1007/s00125-006-0159-x

Kulzer, B., Hermanns, N., Gorges, D., Schwarz, P., \& Haak, T. (2009). Prevention of diabetes self- management program (PREDIAS): effects on weight, metabolic risk factors, and behavioural outcomes. Diabetes Care, 32, 1143-1146. doi: 10.2337/dc08-2141

Loo, T., Davis, R., Lipsitz, L., Irish, J., Bates, C., Agarwal, K....Hamel, B. (2011).

Electronic medical record reminders and panel management to improve primary care of elderly patients. Arch Intern Med, 171, 1552-1558.

doi: 10.1001/archinternmed.2011.394

Melnyk, B.M., \& Fineout-Overholt, E. (2011). Evidence-based practice in nursing \& healthcare: a guide to best practice. In E. Fineout-Overholt, S.B. Stillwell, K.M. Williamson, J.F. Cox, \& B.W. Robbins (Eds.), Teaching evidence-based practice in academic settings (pp. 291-329). Philadelphia, PA: Wolters Kluwer/Lippincott Williams \& Wilkins.

National Institute of Diabetes and Digestive and Kidney Disease. (2008). National diabetes statistics, 2007 fact sheet. Retrieved from http://diabetes.niddk.nih.gov/ $\mathrm{dm} /$ pubs/statistics/index.htm

Nicol, G., Morrato, E., Johnson, M., Campagna, E., Yingling, M., Pham, V., \& Newcomer, J. (2011). Implementation of a glucose screening program based on diffusion of innovation theory methods. Psychiatric Services, 62, 12-14. doi: 10.1176/appi.ps.62.1.12 
Norris, S. L., Zhang, X., Avenell, A., Gregg, E., Schmid, C.H., \& Lau, J. Long-term non-pharmacological weight loss interventions for adults with prediabetes. Cochrane Database of Systematic Reviews 2005, Issue 2. Art. No.: CD005270. DOI: 10.1002 /14651858.CD005270.

O’Connor, P., Crain, A., Rush, W., Sperl-Hillen, J., Gutenkauf, J., \& Duncan, J. (2005). Impact of an electronic medical record on diabetes quality of care. Annals of Family Medicine, 3, 300-306. doi: 10.1370/afm.327

Player, M., Gill, J., Mainous III, A., Everett, C., Koopman, R., Diamond, J....Chen, Y. (2010). An electronic medical record-based intervention to improve quality of care for gastro-esophageal reflux disease (GERD) and atypical presentations of GERD. Quality in Primary Care, 18, 223-229.

Retrieved from http://web.ebscohost.com.www.libroxy.www.wvu.edu/ehost/pdfviewer

Riley, M., Galang, S., \& Green, L. (2011). The impact of clinical reminders on prenatal care. Family Medicine, 43, 560-565. Retrieved from www.stfm.org/fmhub/fm2011/September/Margaret560.pdf

Rogers, E.M. (1995). Diffusion of Innovations, $4^{\text {th }}$ edition. New York, NY: A Division of Simon \& Schuster Inc. Retrieved from http://books.google.com/books

Rolka, D., Burrows, N., Li, Y., \& Geiss, L. (2008). Self-Reported prediabetes and risk reduction activities-United States, 2006. MMWR: Morbidity and Mortality Weekly Report, 2008, 57(44), 1203-1205. Retrieved from CINAHL AN: 2010104375

Saleem, J., Patterson, E., Militello, L., Render, M., Orshansky, G., \& Asch, S. (2005). Exploring barriers and facilitators to the use of computerized clinical reminders. Journal of the American Medical Informatics Association, 12, 438-447. doi: 10.1197/jamia.M1777 
Scott, S., Plotnikoff, R., Karunamuni, N., Bize, R., \& Rodgers, W. (2008). Factors influencing the adoption of an innovation: An examination of the uptake of the Canadian Heart Health (HHK). Implementation Science, 3, 1-8. doi: 10.1186/1748-5908-3-41

Scottish Intercollegiate Guidelines Network (2008). Critical appraisal: Notes and checklist. [on line]. Available: www.sign.ac.uk/methodology/checklist.html

Sequist, T., Gandhi, T., Karson, A., Fiskio, J., Bugbee, D., Sperling, M.,...Bates, D. (2005). A randomized trial of electronic clinical reminders to improve quality of care for diabetes and coronary artery disease. Journal of American Medical Informatics Association, 12, 431-437. doi: 10.1197/jamia.M1788

Shelley, D., Tseng, T., Matthew, A., Wu, D., Ferrari, P., Cohen, A., ...Kopal, H. (2011). Technology -driven intervention to improve hypertension outcomes in community health centers. The American Journal of Managed Care, 17, SP103-110. Retrieved from http://web.ebscohost.com.www.libproxy.wvu.edu/ehost/pdfviewer/pdfviewer?vid=3\&hid =107\&sid=2afad666-076c-4eed-a19c-f0a9a63fc9ed\%40sessionmgr110

Shojania, K.G., Jennings, A., Mayhew, A., Ramsay,C.R., Eccles, M.P., \& Grimshaw, J. (2009). The effects of on-screen, point of care computer reminders on processes and outcomes of care. Cochrane Database of Systematic Reviews 2009, 3, Art. No.: CD001096.

Doi: 10.1002/14651858.CD001096.pub2

United Health Group. (2010). The united states of diabetes: Challenges and opportunities in the decade ahead. Retrieved from www.unitedhealthgroup.com/hrm/UNH_Workingpaper5.pdf WV Health Statistics Center. (2007). WV Behavior risk factor surveillance system 
2000-2006. Retrieved from

http://www.wvdiabetes.org/Portals/12/Diabetes\%20in\%20wv.ppt

Winer, N., \& Sowers, J. (2004). Epidemiology of diabetes. The Journal of Clinical

Pharmacy, 44, 397-405. doi: 10.1177/0091270004263017

Wirt County Health Care Association. (2009). Diagnoses productivity report. [Data file].

Wirt County Health Care Association. (2009). Mission Statement. Retrieved from the Strategic Plan 2009.

Yamaoka, K., \& Tango, T. (2005). Efficacy of lifestyle education to prevent type 2 diabetes.

Diabetes Care, 28, 2780-2786. doi: 10.2337/diacare.28.11.2780 
Table 1

Diffusion of Innovation Process

Five Stages in the Decision Innovation

Process

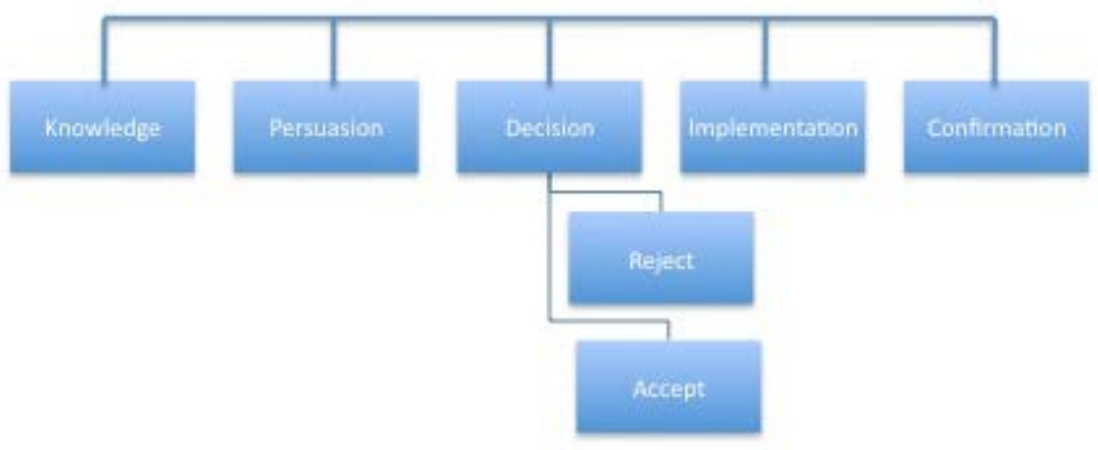

Note. The five stages in Rogers Diffusion of Innovations Theory are from Rogers (2004). The image is from http://en.wikipedia.org/wiki/Diffusion_of_innovations. 
Appendix A

1301 Elizabeth Pike, PO Box 609

Elizabeth, WV 26143

$\begin{array}{ll}\text { Wirt County Health Services Association, Inc. } & \begin{array}{l}\text { Phone: (304) } 275-3301 \\ \text { Fax: }\end{array} \\ \text { (304) } 275-4798\end{array}$

March 1, 2012

To Whom It May Concern:

This letter is to inform you that I, Dee Scritchfield, CEO, agrees to and fully support the practice change related to prediabetes that Murrita Bolinger, MSN, FNP-BC will be conducting at our offices located at River Valley Health and Wellness in Ravenswood, WV; Ripley Family Medicine in Ripley, WV; and Coplin Memorial Community Center Health Center in Elizabeth, WV.

If you have any questions in regards to this please do not hesitate to contact me.

Sincerely,

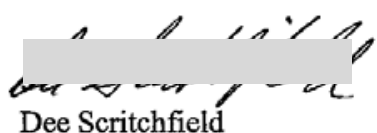

Dee Scritchfield

Chief Executive Officer

Coplin Memorial Community Health Center 1301 Elizabeth Pike, PO Box 609, Elizabeth, WV 26143 Phone: (304) 275-3301 Fax: (304) 275-4798 River Valley Health \& Wellness Center 606 Washington Strect, PO Box 157, Ravenswood, WV 26164 Phone: (304) 273-1033 Fax: (304) 273-1034 River Valley Pharmacy 606 Washington Street, PO Box 157, Ravenswood, WV 26164 Phone: (304) 868-6050 Fax: (304) 868-2048 Ripley Family Medicine 512A S Church Street, Ripley, WV 25271 Phone: (304) 372-1033 Fax: (304) 373-0223 Jackson County Schools Wellness Center 4A School Street, Ripley, WV 25271 Phone \& Fax: (304) 372-7341 Wirt County Schools Wellness Center \#3 Schoolview Street, PO Box 400, Elizabeth, WV 26143 Phone:(304) 275-3117 Fax: (304) 275-7255 Southern Local Schools Wellness Center 906 Elm Street, Racine, OH 45771 Phone: (740) 949-2348 Fax: (740) 949-2536 
Appendix B

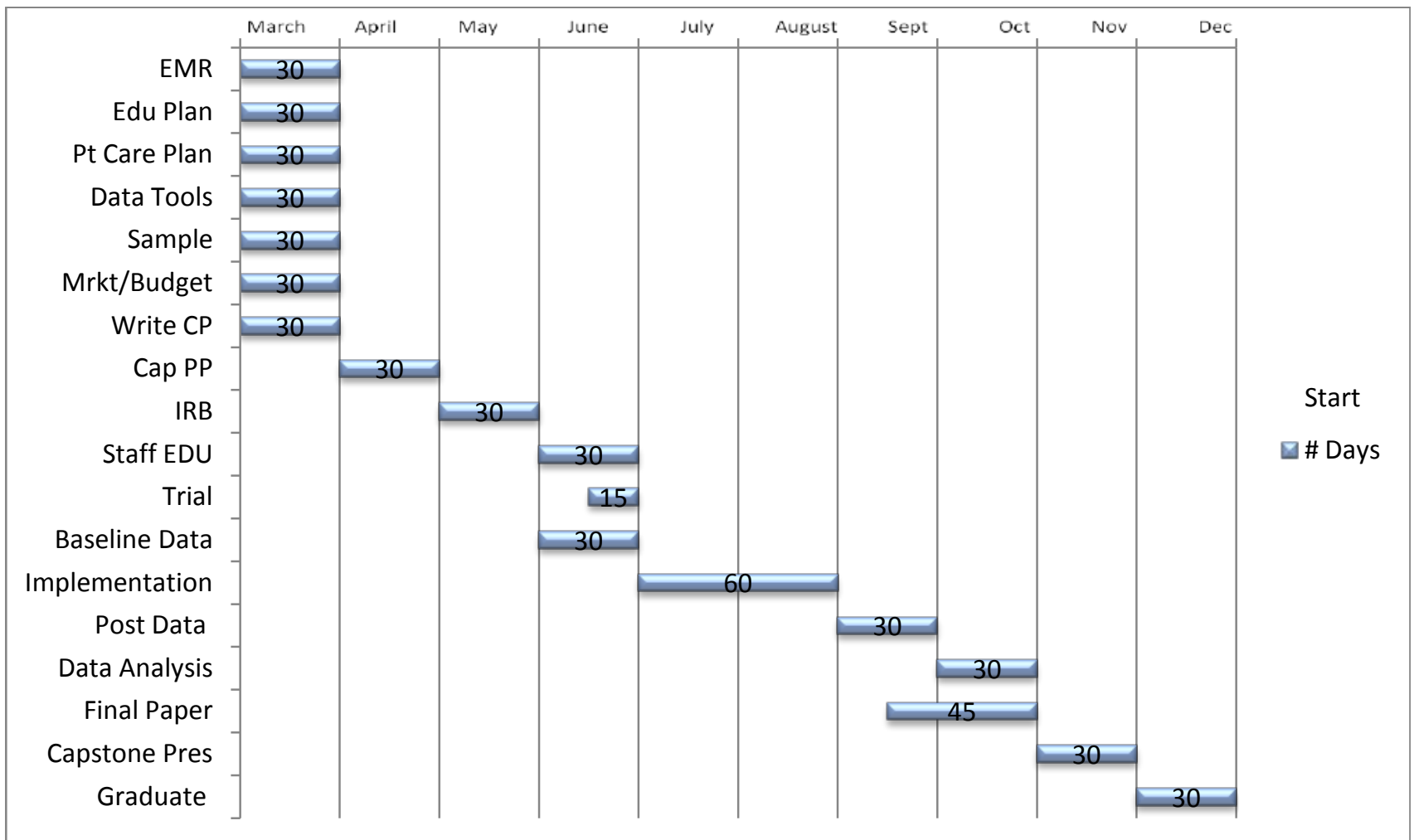




\section{Appendix C}

Prediabetes Heightening the Awareness

Education Outline

I. Overview of Prediabetes
A. History of terms
B. ICD codes

II. Definition of Prediabetes
A. Fasting glucose
B. Oral glucose tolerance test
C. Hemoglobin A1C
D. Comparison of different organizations
1. American Diabetes Association
2. World Health Organization

III. Significance of the Problem
A. United States
B. State of West Virginia
C. Locally

IV. Statement of the Problem

V. Risk Factors for Prediabetes
A. Nutrition
B. Weight
C. Physical Inactivity
D. Other

VI. Testing for Prediabetes

VII. Intervention for Prevention
A. Diet
B. Physical Activity
C. Medication

VIII. Electronic Medical Reminder (EMR) innovation
A. Triggers for EMR reminder
B. Location of EMR reminder

1. Health tab

2. Labeled "Prediabetes/Diabetes risk"

C. Information provided from EMR reminder

1. Screening options

2. Order tests from drop down box

D. Results of testing

1. Determination of Prediabetes 
2. Problem list

3. Initiate plans of care

a. Informing patients of diagnosis

b. Follow-up labs

c. Lifestyle Modifications counseling

d. Referral to Dietician

e. Referral to Diabetes Prevention Program

f. Medication 


\section{Appendix D}

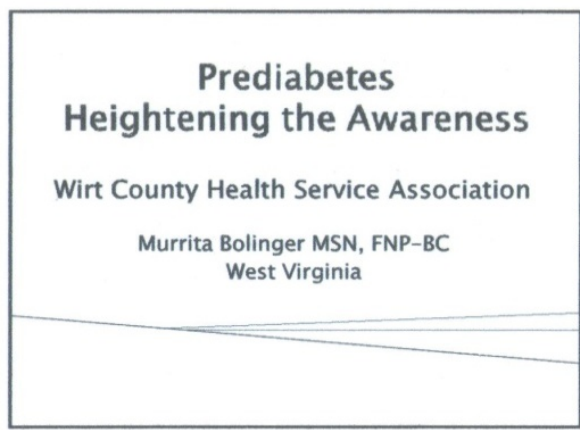

\section{Overview}

- 79 Million Americans

Diagnosed with Prediabetes $(2010)^{3}$

- History of Terms $s^{1,4,7}$

1965 (borderline, chemical, or asymptomatic diabetes)

1965 (borderline, chemical, or as 1979 (impaired glucose tolerance)
2002 (ppedlabetes)

- 2002 (prediabetes)

2005 (impaired fasting glucose, impaired glucose

tolerance)

- Multiple ICD codes

(790.2, 790.29, and 790.21)
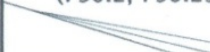

Percentage of Diabetes in US in $2010^{2}$

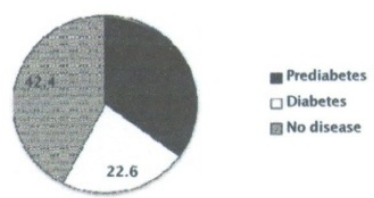

18.8 million Adults with Diabetes mixed with 7 million undiagnosed ${ }^{2}$

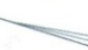

\section{Objectives}

Participants will be able to:

1. Define prediabetes.

2. Discuss risk factors for patients at risk for type 2 diabetes.

3. Discuss proper screening tests for patients at risk for type 2 diabetes.

4. Demonstrate the use of electronic medical record (EMR) reminder process.
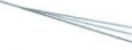

\section{Prediabetes $^{1}$}

- Definition: "an intermediate phase at risk for development of Type 2 Diabetes Mellitus."

Impaired Fasting Glucose (IFG) $\quad 100-125 \mathrm{mg} / \mathrm{dL}$ - Impaired Glucose Tolerance (IGT) 140-199 mg/dL - Hemoglobin AIC (HgbAIC) 5.7\%-6.4\%

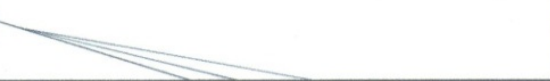

\section{Prevalence of Diabetes ${ }^{2}$}

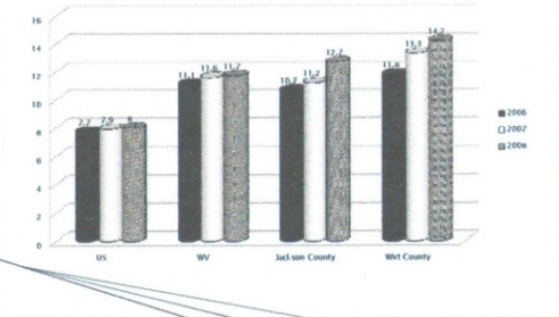



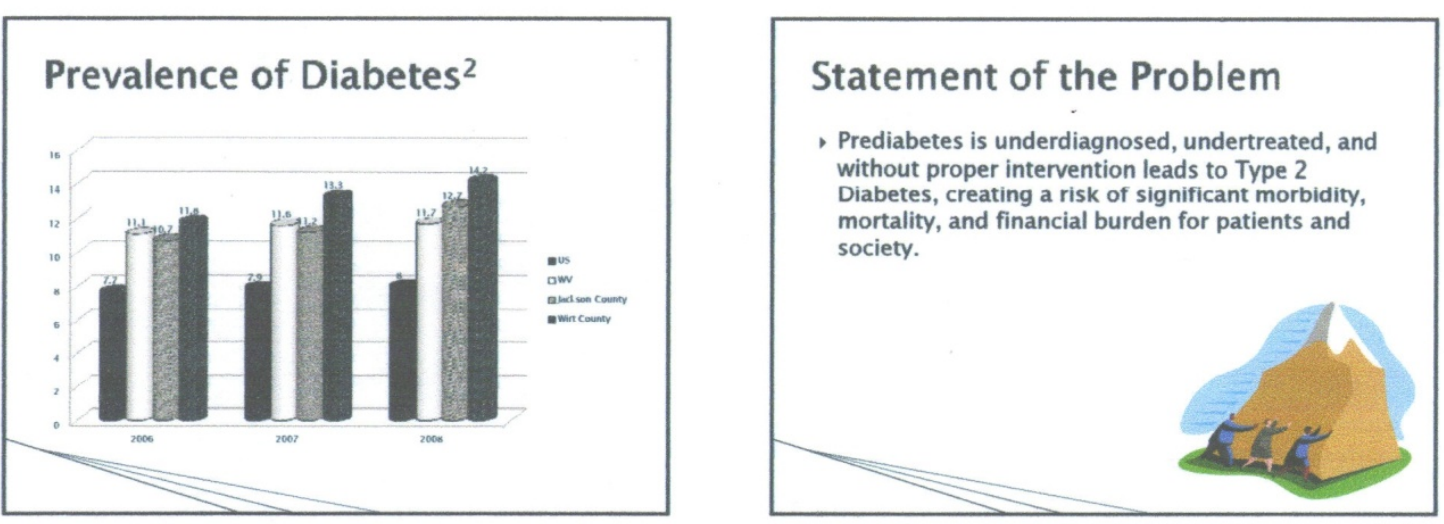

\begin{tabular}{l} 
Risk Factors 1,6 \\
- Hypertension \\
- History of Cardiovascular Disease \\
- Hyperlipidemia \\
- Elevated Triglycerides ( $>250)$ \\
- Low HDL $(<35)$ \\
- Family History of Diabetes \\
- In first degree relative \\
(mother, father, sister, brother) \\
\hline
\end{tabular}

\begin{tabular}{l} 
Risk Factors 1 \\
- Physical Inactivity \\
- Overweight/Obesity \\
- History of IFG, IGT or Elevated AIC \\
- History of PCOS \\
- History of Gestational Diabetes \\
- History of Giving Birth to a baby $>9 \mathrm{lbs}$ \\
- Race: Non-Caucasian \\
- Acanthosis Nigricans \\
\hline
\end{tabular}

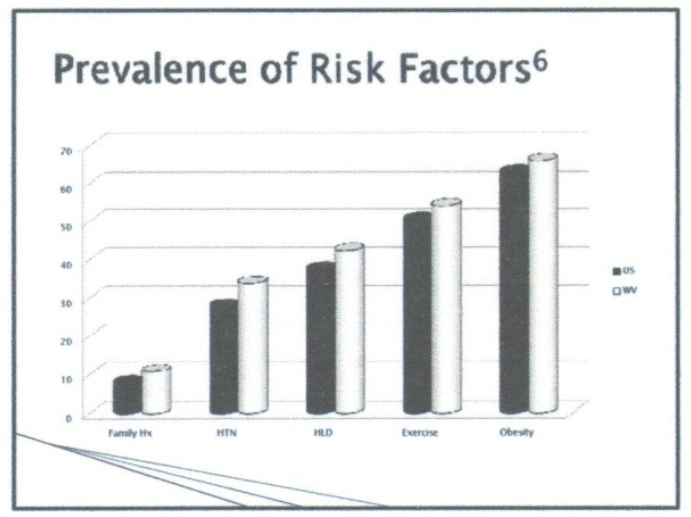

\section{Testing for Prediabetes 1}

- Should be considered in all Adults who are Overweight/Obese (BMI $>25 \mathrm{~kg} / \mathrm{m}^{2}$ and have one or more Risk Factor

- In patients without Risk Factors Testing should begin at Age 45

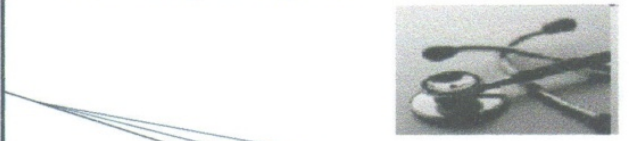




\begin{tabular}{|c|}
\hline Interventions ${ }^{1}$ \\
\hline - Weight Loss of $7 \%$ \\
\hline - Increase Activity to at Least $150 \mathrm{Min} /$ Week \\
\hline $\begin{array}{l}\text { - Moderate Intensity Activity } \\
\text { - Brisk Walking (@ 3mile/hr) } \\
\text { - Water Aerobics } \\
\text { - Bicycling (slow < } 10 \text { miles/hr } \\
\text { - Gardening } \\
\text { - Ballroom Dancing }\end{array}$ \\
\hline
\end{tabular}

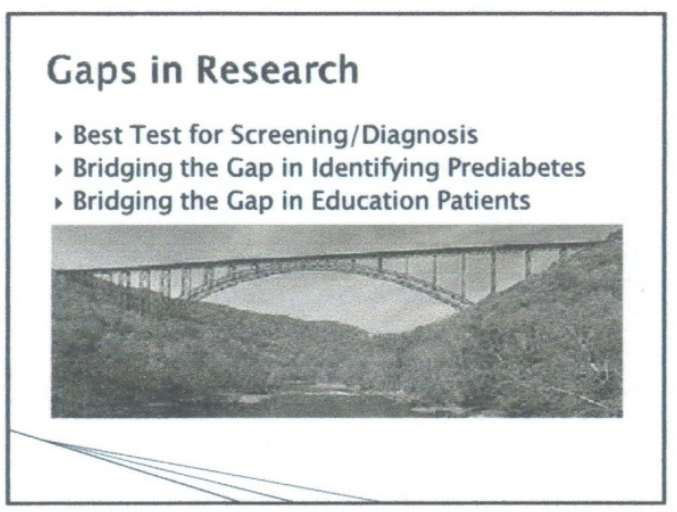

\section{Electronic Reminder}

- Treatment Plan Documentation

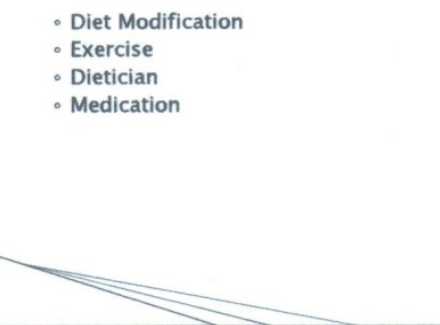

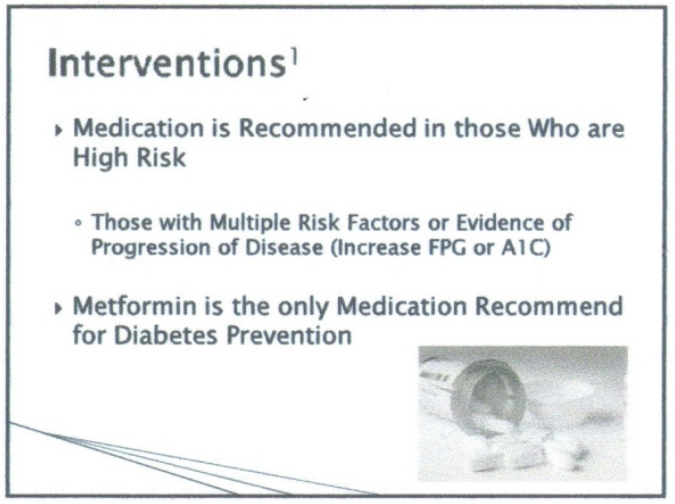

\section{Electronic Reminder}

- ICD Codes will Automatically Trigger

- Prediabetes/Diabetes Risk Tab

- Screening Tests in Drop Down Box

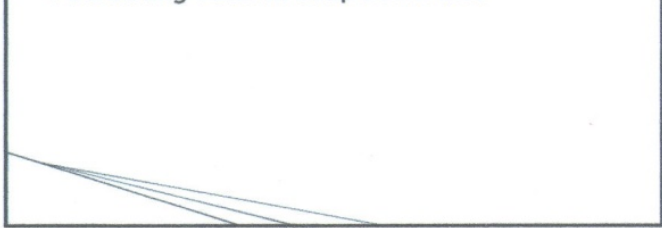



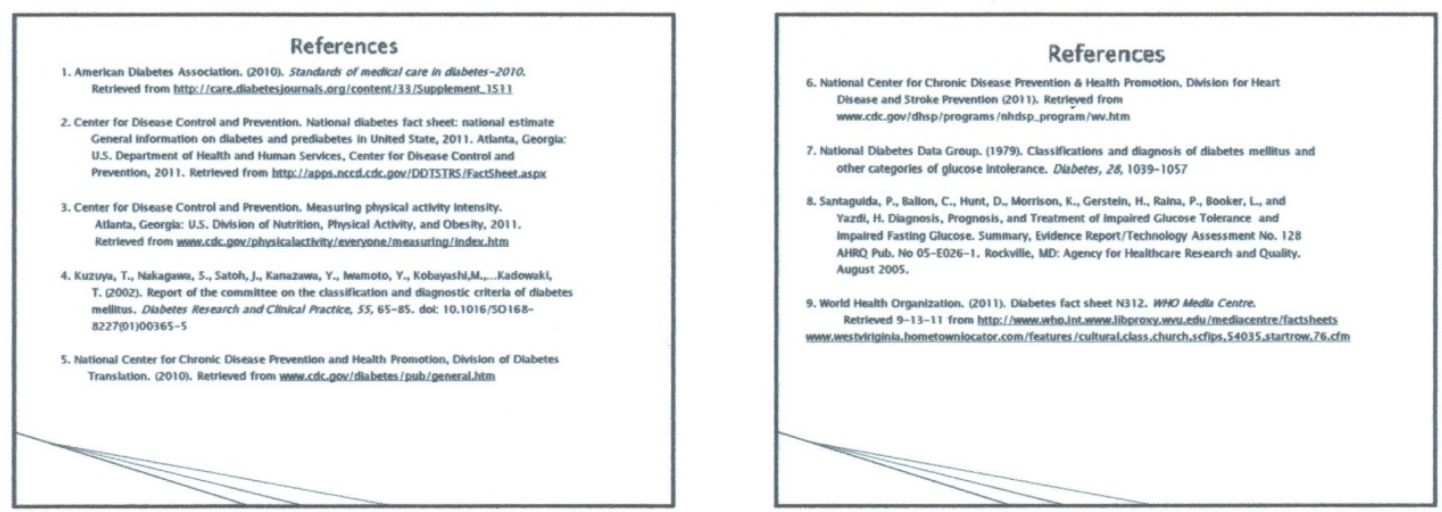


\section{Appendix E}

\section{References for Educational Content Support}

Agency for Healthcare Research and Quality (2005). Diagnosis, prognosis, and treatment of impaired fasting glucose tolerance and impaired fasting glucose. Summary, Evidence Report /Technology Assessment No. 128. (AHRQ Pub. No 05-E026-1). Retrieved from www.ahrq.gov

American Diabetes Association. (2012). Standards of medical care in diabetes-2012. Retrieved from http://care.diabetesjournals.org/content/35/Supplement_1S11

Bureau for Public Health, Health Statistic Center (2009). The burden of diabetes in West Virginia 2009. Retrieved from www.wvdiabetes.org/Portals/12/Diabetes_ Burden_FINAL_20100421withcover.pdf

Center for Disease Control and Prevention. National diabetes fact sheet: national Estimates and general information on diabetes and prediabetes in United States (2011). Atlanta, GA: U.S. Department of Health and Human Service, Center for Disease Control and Prevention, 2011.

Center for Disease Control and Prevention. Measuring physical activity intensity.

Atlanta, Georgia: U.S. Division of Nutrition, Physical Activity, and Obesity, 2011.

Retrieved from www.cdc.gov/physicalactivity/everyone/measuring/index.htm

Diabetes Prevention Program Research Group (2009). 10-year follow-up of diabetes incidence and weight loss in the Diabetes Prevention Outcome Study. Lancet, 374, 1677-1686. doi: 10.1016/S0140-6736(09)61457-4

Diabetes Prevention Program Research Group (2002). The diabetes prevention program (DPP): Description of lifestyle intervention. Diabetes Care, 25, 2165-2171. doi: $10.2337 /$ diacare.25.12.2165 
Diabetes Prevention Program Research Group. (2002). Reduction in the incidence of type 2 diabetes with lifestyle intervention or metformin. The New England Journal of Medicine, 346, 393-403. doi: 10.1056/NEJMoa012512

Hamman, R.F., Wing, R.R., Edelstein, S.L., Lachin, J.M., Bray, G.A., Delahanty, L.,... Wylie-Rosett, J. (2006). Effect of weight loss with liefestyle intervention on risk of diabetes. Diabetes Care, 29, 2102-2107. doi: 10.2337/dc06-0506

Jackson, L. (2009). Translating the diabetes prevention program into practice: A review of community interventions. The Diabetes Educator, 35, 309-320.

doi: $10.1177 / 014572170830153$

Kramer, M.K., Kriska, A.M., Venditti, E.M., Semler, L.N., Miller, R.G., McDonald, T.,... Orchard, T.J. (2010). A novel approach to diabetes prevention: Evaluation of the group lifestyle balance program delivered via DVD. Diabetes Research and Clinical Practice, 90, e60-e63. doi: 10.1016/j.diabres.2010.08.013

Kriska, A.M., Edelstein, R.F., Hamman, R.F., Otto, A., Bray, G.A., Mayer-Davis, E.,... Regensteiner, J.G. (2006). Physical activity in individuals at risk for diabetes: Diabetes prevention program. Medicine \& Science in Sports \& Exercise, 35, 826-832. doi: 10.1249/01.mss.0000218138.91812.f9

Kriska, A.K., Delahanty, L., Hoskin, M., Matulik, M., Otto, A., Pepe, C.,...Wolfe, D. (2005). Fishes, whales, and fishing tips: Hooking an active lifestyle. Diabetes Spectrum, 18, 114-118. doi: 10.2337/diaspect.18.2.114

Kuzuya, T., Nakagawa, S., Satoh, J., Kanazawa, Y., Iwamoto, Y., Kobayashi, M.,...Kadowaki, T. (2002). Report of the committee on the classification and diagnostic criteria of diabetes mellitus. Diabetes Research and Clinical Practice, 55, 65-85. doi: 10.1016/SO168-8227(01)00365-5 
National Center for Chronic Disease Prevention and Health Promotion, Division of Diabetes Translation. (2010). Retrieved from www.cdc.gov/diabetes/pub/general.htm

National Center for Chronic Disease Prevention \& Health Promotion, Division for Heart Disease and Stroke Prevention (2011). Retrieved from www.cdc.gov/dhsp/programs/nhdsp_program/wv.htm

National Diabetes Data Group. (1979). Classifications and diagnosis of diabetes mellitus and other categories of glucose intolerance. Diabetes, 28, 1039-1057

Orchared, T.J., Temprosa, M. Goldberg, R., Haffner, S., Ratner, R., Marcovina, S., \& Fowler, S. (2005). The effect of metformin and intensive liefestyle intervention on the metabolic syndrome: The diabetes prevention program randomized trial. Annuals of Internal Medicine, 142, 611-619. Retrieved from http://web.ebscohost.com.www.libroxy.wvu. edu/ehost/pdfviewer/pdfviewer?vid=38\&hid=218sid0f85ad33-8a8

Sacks, F.M., Bray, G.A., Carey, V.J., Smith, S.R., Ryan, D.H., Anton, S.D.,...Williamson, D.A. (2009). Comparison of weight-loss diets with different compositions of fat, protein, and carbohydrates. The New England Journal of Medicine, 360, 859-873. Retrieved from http://www.nejm.org.www.libroxy.wvu.edu/doi/pdf/10.1056/NEJMoa0804748

Santaguida, P., Balion, C., Hunt, D., Morrison, K., Gerstein, H., Raina, P., Booker, L., and Yazdi, H. Diagnosis, Prognosis, and Treatment of Impaired Glucose Tolerance and Impaired Fasting Glucose. Summary, Evidence Report/Technology Assessment No. 128 AHRQ Pub. No 05-E026-1. Rockville, MD: Agency for Healthcare Research and Quality. August 2005.

Venditti, E. (2007). Efficacy of lifestyle behavior change programs in diabetes. Current Diabetes Reports, 7, 123-127. Retrieved from http://springerlink.com.www.libroxy.wvu. edu/content/1534-4827/7/2

Wing, R.R. \& Phelan, S. (2005). Long-term weight loss maintenance. American Journal of 
Clinical Nutrition, 82, 222S-2225S. Retrieved from http://www.ajcn.org.www.libroxy. wvu.edu/content/82/1/222S.full.pdf+html

World Health Organization. (2011). Diabetes fact sheet N312. WHO Media Centre.

Retrieved 9-13-11from

http://www.who.int.www.libproxy.wvu.edu/mediacentre/factsheets

www.westviriginia.hometownlocator.com/features/cultural,class,church,scfips,54035, startrow,76.cfm 


\section{Appendix F}

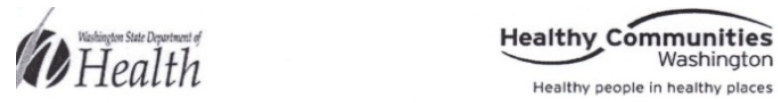

ALGORITHM: Pre-Diabetes Identification and Intervention

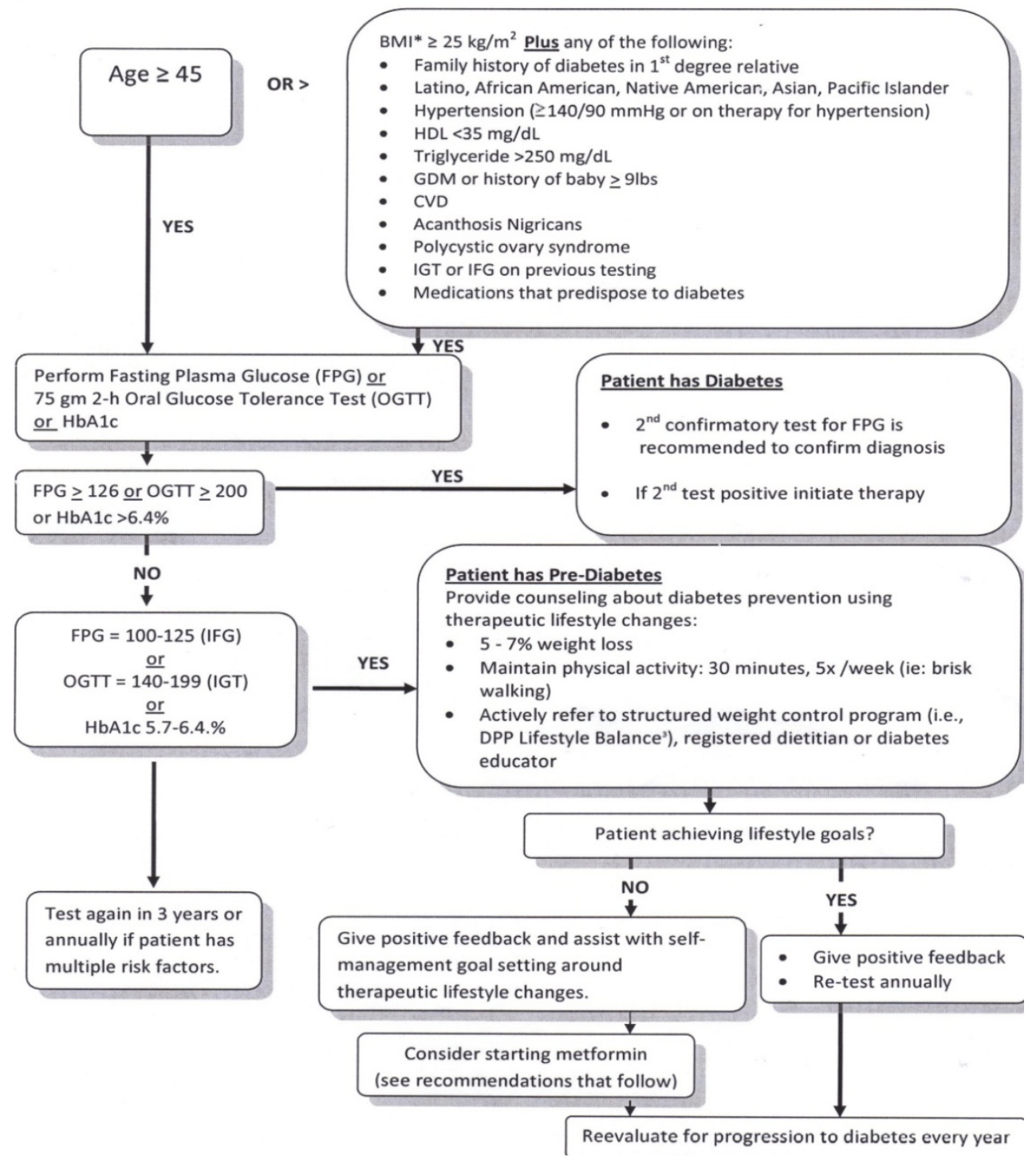


Common ICD-9 Codes for Diabetes Screening

\begin{tabular}{|l|l|}
\hline V77.1 & Diabetes Screening \\
\hline 790.21 & Impaired Fasting Glucose \\
\hline 790.22 & Impaired Glucose Tolerance \\
\hline 278.00 & Obesity \\
\hline 278.02 & Overweight \\
\hline
\end{tabular}

CPT Codes for Diabetes Screening

\begin{tabular}{|l|l|}
\hline CPT 82947 & Fasting Plasma Glucose Test \\
\hline CPT 82950 & Post-meal Glucose \\
\hline CPT 82951 & Oral Glucose Tolerance Test \\
\hline CPT 83036 & Hemoglobin A1C \\
\hline
\end{tabular}

Medicare covers one glucose test/year if never previously tested, one test/year if previously tested and not diagnosed with pre-diabetes and two tests/year for individuals with pre-diabetes.

Screening:

- Testing to detect pre-diabetes and type 2 diabetes in asymptomatic people should be considered in adults who are overweight or obese $\left(\mathrm{BMI} \geq 25 \mathrm{~kg} / \mathrm{m}^{2}\right)$ and who have one or more additional risk factors for diabetes. In thos $\epsilon$ without these risk factors, testing should begin at age 45 . (B)

- To test for pre-diabetes or diabetes, either an FPG test or a 2-h OGTT (75-g glucose load) or HbA1c or all are appropriate. (B)

- An OGTT may be considered in patients with Impaired Fasting Glucose (IFG) to better define the risk of diabetes. (E)

\section{Prediabetes Treatment:}

The Diabetes Prevention Program (DPP) lifestyle intervention was significantly more effective in reducing the incidence of diabetes ( $58 \%$ lifestyle vs $31 \%$ metformin) as compared with placebo.

- Patients with Impaired Glucose Tolerance (IGT) (A) or IFG (E) should be given counseling on weight loss of 5-7\% of body weight, as well as on increasing physical activity to at least $150 \mathrm{~min} /$ week of moderate activity such as walking.

- Although the effectiveness of metformin was about half that achieved with lifestyle modification, substantially greater benefit was seen in a subset of younger and obese individuals. In addition to lifestyle counseling, metformin may be considered in those who are at very high risk (combined IFG and IGT plus other risk factors) and who are obese and under 60 years of age. (E)

- Monitoring for the development of diabetes in those with pre-diabetes should be performed every year. (E)

Off-label use of metformin, based on the Diabetes Prevention Program: starting dosage 500 mg a day with food, increase dose every 1-2 weeks, to achieve clinically effective dose of 1500-2000 mg/day, based on tolerability.

ADA evidence-grading system for clinical practice recommendations:

(A): Clear evidence from well-conducted, generalizable, randomized controlled trials. (B): Supportive evidence from wellconducted cohort studies. (C): Supportive evidence from poorly controlled or uncontrolled studies. (E): Expert consensus or clinical experience.

Jriginally prepared by the Diabetes Primary Prevention Initiative based on American Diabetes Association (2008) Clinical Practice Recommendations. Revised by Nashington State Department of Health Diabetes Prevention and Control Program based on ADA 2010 Clinical Practire Rernmmentatinnc 


\section{Appendix G}

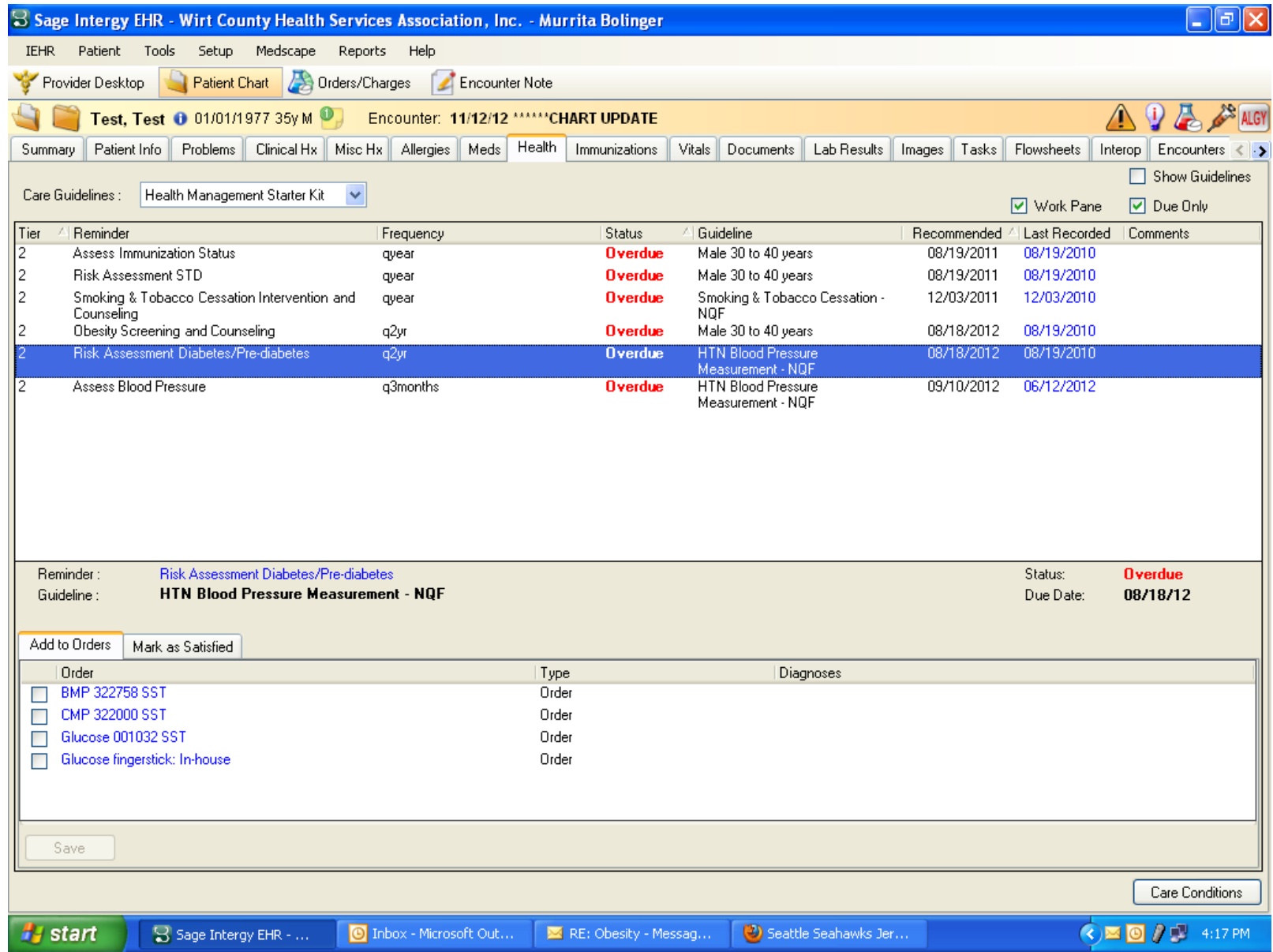




\section{Appendix $\mathbf{H}$}

Patient ID:

$\square$ Male $\square$ Female

Age:

Vital Signs/Labs:

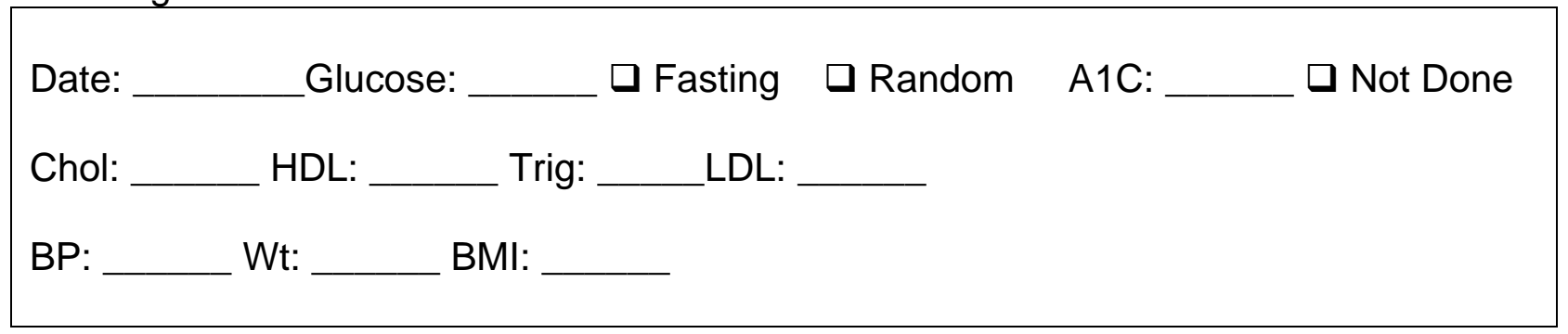

Date:

Glucose: $\square$ Fasting $\square$ Random A1C: $\square$ Not Done

Does patient qualify for screening?

$\square$ Yes $\square$ No

Was the patient screened for prediabetes?

$\square$ Yes $\square$ No

Was the patient diagnosed with prediabetes?

$\square$ Yes $\square$ No

Is there evidence to support a prediabetes diagnosis?

$\square$ Yes $\square$ No

Is there evidence of a treatment plan?

$\square$ Yes

$\square$ No

$\square$ Follow-up labs $\square$ lifestyle change $\square$ referral to dietitian $\square$ medication 


\section{Appendix I}

Estimated

Actual

Total Expenses $\$ 2958.07$

$\$ 93.40$

\begin{tabular}{|l|l|l|}
\hline EMR Reminder Development & & \\
\hline $\begin{array}{l}\text { Formal Brainstorming } \\
\text { Meeting: Project Leader, } \\
\text { Project Mentor, and CNM } \\
(1 \mathrm{hr})\end{array}$ & & \\
\hline $\begin{array}{l}\text { EMR script design: Project } \\
\text { Leader and Project Mentor } \\
\text { (4hrs) }\end{array}$ & $\$ 132.00$ & $\$ 0$ \\
\hline Computer & & $\$ 0$ \\
\hline Space & $\$ 533.00$ & $\$ 0$ \\
\hline Legal Pad-notes 4 pads/pack & $\$ 0$ & $\$ 8.94$ \\
\hline Total EMR Reminder Development & $\$ 0$ & $\$ \mathbf{8 . 9 4}$ \\
\hline
\end{tabular}

\begin{tabular}{|c|c|c|}
\hline \multicolumn{3}{|l|}{ Education Plan Development } \\
\hline \multirow{12}{*}{$\begin{array}{l}\text { Materials } \\
\text { Content Outline } \\
\text { Pre and Post Knowledge Test } \\
\text { Power Point Presentation } \\
\text { Printed Hand-Outs: } \\
\text { Clinical Practice Guidelines } \\
\text { Diabetes Risk Test } \\
\text { Algorithm: Pre-Diabetes } \\
\quad \text { Identification and } \\
\text { Intervention } \\
\text { ADA Screening Guideline } \\
\text { Reference List for Providers } \\
\text { (Project Leader's Time: } 8 \text { hrs) }\end{array}$} & \multirow[b]{12}{*}{$\$ 304.00$} & \multirow[b]{12}{*}{$\$ 0$} \\
\hline & & \\
\hline & & \\
\hline & & \\
\hline & & \\
\hline & & \\
\hline & & \\
\hline & & \\
\hline & & \\
\hline & & \\
\hline & & \\
\hline & & \\
\hline Computer & $\$ 0$ & $\$ 0$ \\
\hline Space & $\$ 0$ & $\$ 0$ \\
\hline \multicolumn{2}{|c|}{ Total Education Plan Development } & $\$ 0$ \\
\hline
\end{tabular}




\begin{tabular}{|l|r|r|}
\hline Tool Development & & \\
\hline $\begin{array}{l}\text { Data Collection Tool } \\
\text { (5-6 hrs due to Project }\end{array}$ & & \\
$\begin{array}{l}\text { Leader's inexperience with } \\
\text { creating tools) }\end{array}$ & $\$ 190.00$ & $\$ 0$ \\
\hline Total Tool Development & & $\$ 0$ \\
\hline
\end{tabular}

\begin{tabular}{|c|c|c|}
\hline \multicolumn{3}{|l|}{ Education Intervention } \\
\hline $\begin{array}{l}\text { Education Session x } 3 \text { sites } \\
(1 \mathrm{hr})\end{array}$ & $\$ 734.00$ & $\$ 0$ \\
\hline Conference Room & $\$ 0$ & $\$ 0$ \\
\hline $\begin{array}{l}\text { Equipment: } \\
\text { Computer, Projector, and } \\
\text { PolyCom network/TV } \\
\end{array}$ & $\$ 0$ & $\$ 0$ \\
\hline $\begin{array}{l}\text { Lunch for } 3 \text { sites: } \\
\text { Food } \\
\text { Paper supplies (plates, } \\
\text { napkins, cups, and plastic } \\
\text { ware) } \\
\text { Drinks } \\
\text { \$10/ person } \\
\end{array}$ & $\begin{array}{l}\text { RVHW - } 8 \\
\text { RFM - } 4 \\
\text { Coplin - } 9 \\
\text { X } 21 \\
\end{array}$ & $\$ 0$ \\
\hline $\begin{array}{l}\text { Contact Pharmaceutical } \\
\text { Companies for } 3 \text { sites-lunch } \\
(1 \mathrm{hr})\end{array}$ & $\$ 38.00$ & $\$ 0$ \\
\hline $\begin{array}{l}\text { Pens (Knowledge Test) x } 2 \\
\text { 30/pack @ } 7.47\end{array}$ & $\$ 7.47$ & $\$ 0$ \\
\hline $\begin{array}{l}\text { Copies for Provider/Project } \\
\text { Champion Packets x 15: } \\
\text { Pre and Post test ( } 4 \text { pages) } \\
\text { Diabetes Risk Test (1 page) } \\
\text { CPG (50 pages) } \\
\text { ADA screening guide (1 pg) } \\
\text { Algorithm ( } 2 \text { pages) } \\
\text { Reference List (4 pages) }\end{array}$ & Total 62 pages per packet: & \\
\hline $.10 £$ per copy & $\$ 93.00$ & $\$ 0$ \\
\hline
\end{tabular}




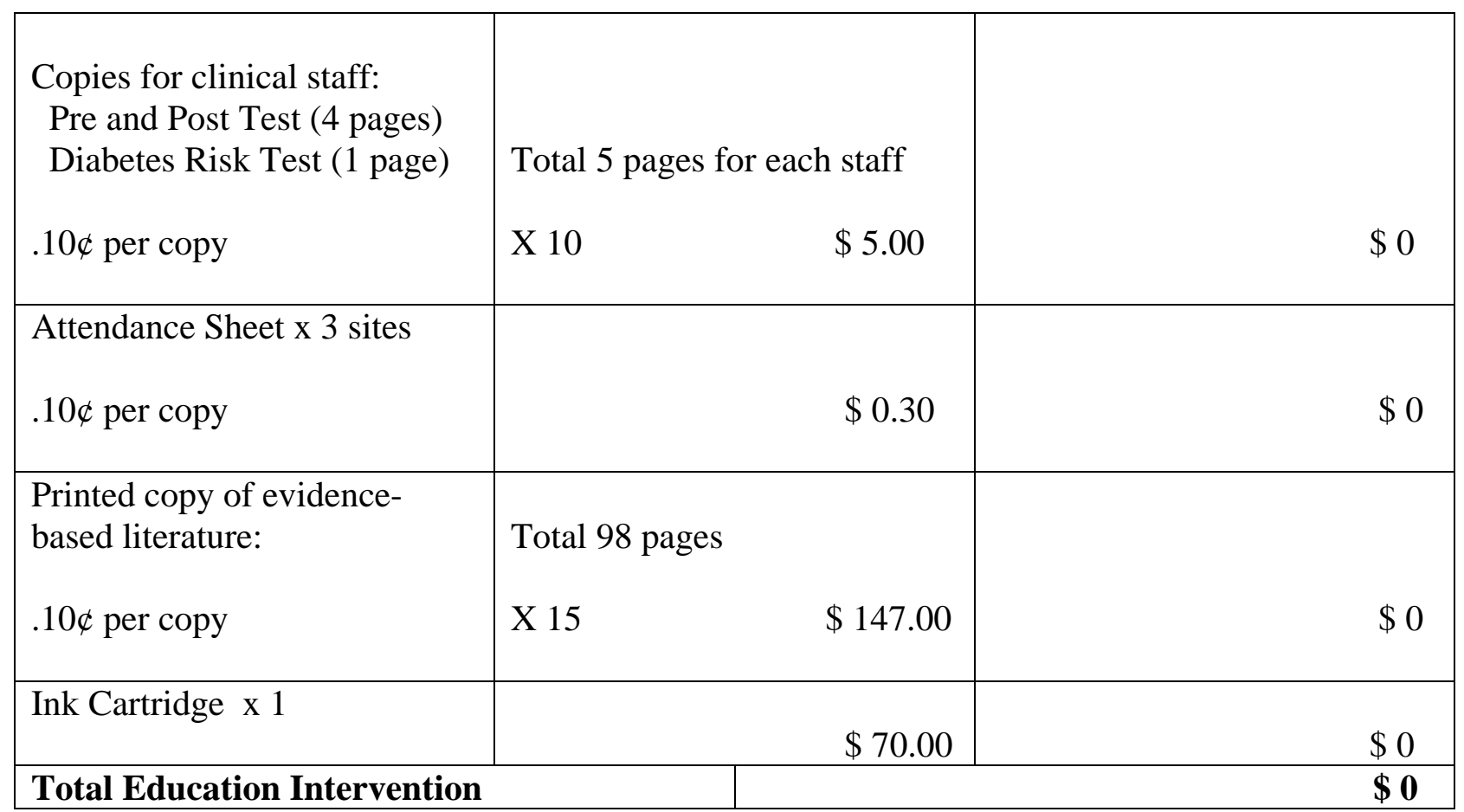

\begin{tabular}{|c|c|c|}
\hline Marketing & & \\
\hline $\begin{array}{l}\text { Staff Meeting Announcement } \\
\text { X } 3 \text { sites for } 10 \text { minutes }\end{array}$ & $\$ 188.00$ & $\$ 0$ \\
\hline $\begin{array}{l}\text { Exam Rooms x } 19 \\
\text { Diabetes Risk Test }\end{array}$ & & \\
\hline $.10 థ$ per copy & $\$ 1.90$ & $\$ 0$ \\
\hline $\begin{array}{l}\text { Lobby Bulletin Boards } \\
\text { Each site } 2 \text { prints/laminated: } \\
\text { "The Healthy Plate" } \\
\text { "You Have the Power to } \\
\text { Prevent Diabetes" }\end{array}$ & $\begin{array}{l}\text { Total } 6 \text { prints } 11 \times 17 \\
\text { laminated at } \$ 5.00 \text { each } \\
\qquad \$ 30.00\end{array}$ & $\$ 30.00$ \\
\hline Total Marketing & & $\$ 30.00$ \\
\hline
\end{tabular}

\begin{tabular}{|l|l|l|}
\hline Misc. & \\
\hline Communication with Project & & \\
Champions 3 sites: Project & & \\
Leader, Project Mentor, and & & \\
two NP, who are serving as & & \\
Project Champions. & & \\
\hline
\end{tabular}




\begin{tabular}{|c|c|c|c|}
\hline $\begin{array}{l}\text { Project Leader plus } \\
\text { Phone x } 4 \text { calls at } 15 \text { minutes. } \\
1 \text { hour given for every other } \\
\text { weekly phone meeting plus } \\
\text { time needed for orienting new } \\
\text { employees or site students. } \\
\text { ( } 1 \text { hr each Champion) }\end{array}$ & & $\$ 211.00$ & $\$ 0$ \\
\hline $\begin{array}{l}\text { Site Visits: } \\
\text { Gas x } 4 \text { trips at \$3.89/gallon } \\
\text { RVHW: Hometown } 0 \\
\text { RFM: } 22 \text { miles x } 1 \text { trip } \\
\text { Coplin: } 55 \text { miles x } 1 \text { trip } \\
\text { Avg. } 22 \text { miles/ gallon }\end{array}$ & Total 308 miles & $\$ 54.46$ & $\$ 54.46$ \\
\hline
\end{tabular}




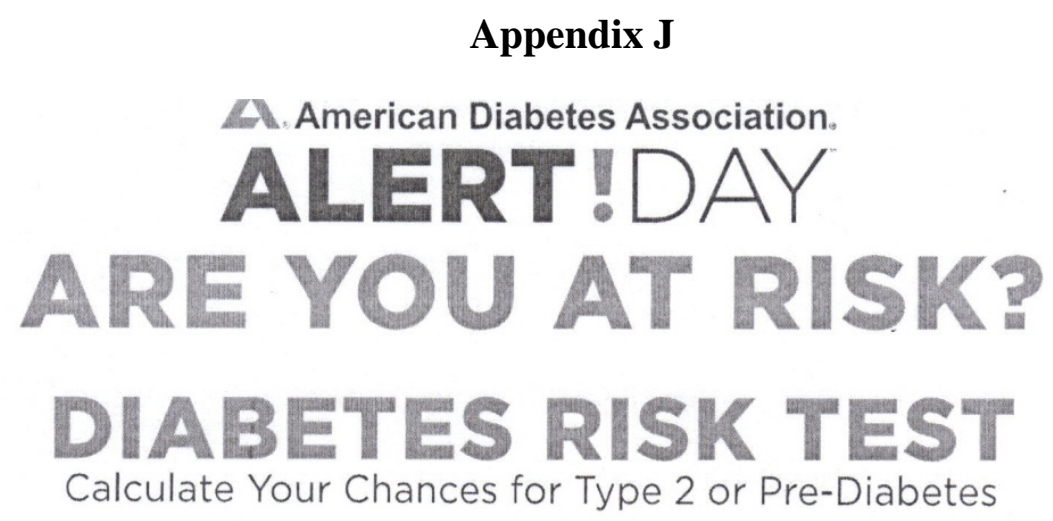

The American Diabetes Association has revised its Diabetes Risk Test according to a new, more accurate statistical model. The updated test includes some new risk factors, and projects risk for pre-diabetes as well as diabetes.

This simple tool can help you determine your risk for having pre-diabetes or diabetes. Using the flow chart, answer the questions until you reach a colored shape. Match that with a risk message shown below.

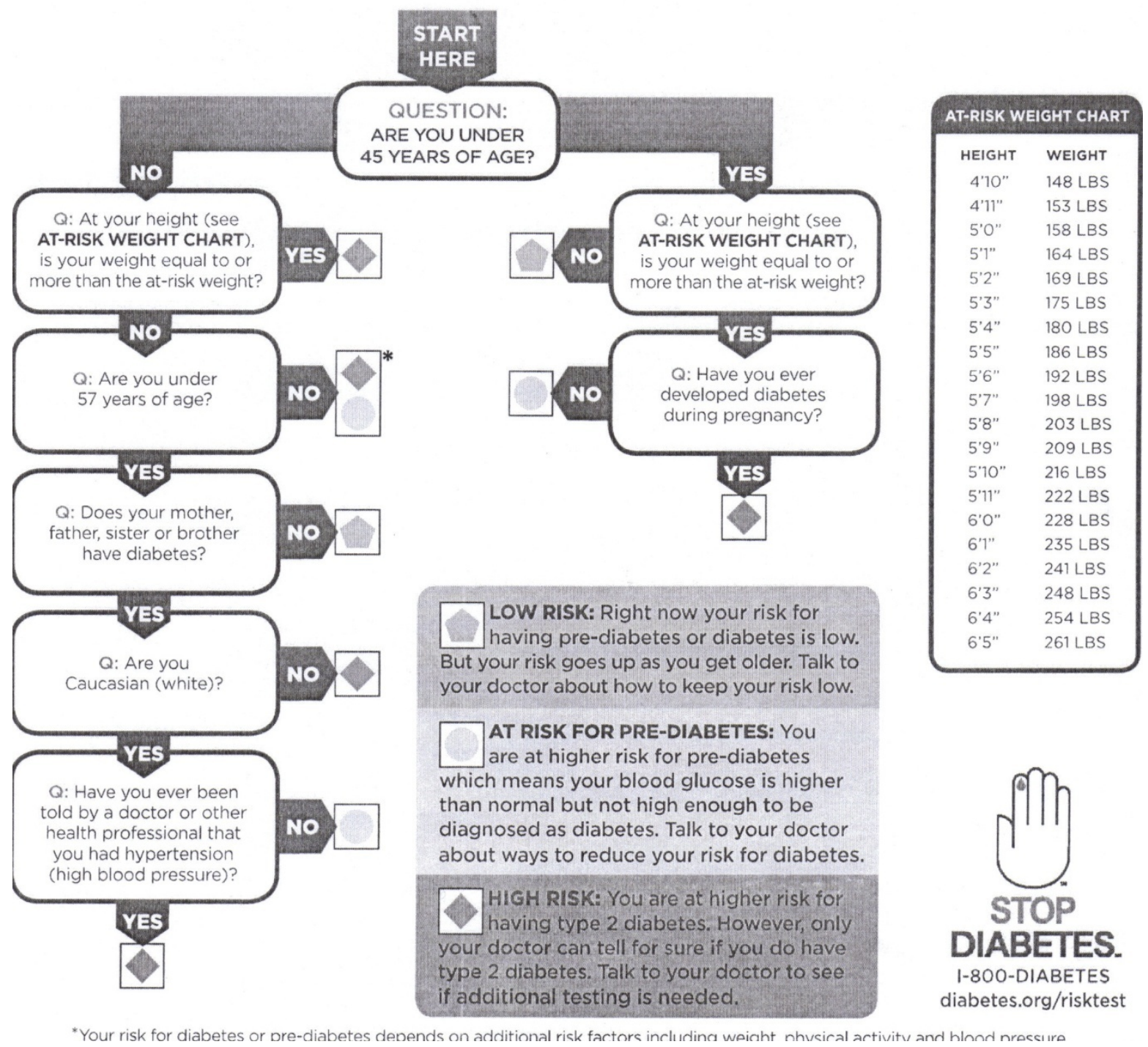


Appendix K

Date: Time:

\section{ATENDING:}

$\begin{array}{ll}1 . & 15 . \\ \text { 2. } & 16 . \\ \text { 4. } & 17 . \\ 5 . & 18 . \\ 6 . & 20 . \\ 7 . & 21 . \\ 8 . & 22 . \\ 9 . & 24 . \\ 10 & 26 \\ 12 \\ 13 . & 27 . \\ 14 . & 28 .\end{array}$

COMMENTS:

FOLLOW UP NEEDED ON THE FOLLOWING:

Minutes Taken By: 